\title{
Sheddable Coatings for Long-Circulating Nanoparticles
}

\author{
Birgit Romberg, ${ }^{1}$ Wim E. Hennink, ${ }^{1}$ and Gert Storm ${ }^{1,2}$
}

Received March 2, 2007; accepted May 14, 2007; published online June 6, 2007

\begin{abstract}
Nanoparticles, such as liposomes, polymeric micelles, lipoplexes and polyplexes are frequently studied as targeted drug carrier systems. The ability of these particles to circulate in the bloodstream for a prolonged period of time is often a prerequisite for successful targeted delivery. To achieve this, hydrophilic 'stealth' polymers, such as poly(ethylene glycol) (PEG), are used as coating materials. Such polymers shield the particle surface and thereby reduce opsonization by blood proteins and uptake by macrophages of the mononuclear phagocyte system. Yet, after localizing in the pathological site, nanoparticles should deliver their contents in an efficient manner to achieve a sufficient therapeutic response. The polymer coating, however, may hinder drug release and target cell interaction and can therefore be an obstacle in the realization of the therapeutic response. Attempts have been made to enhance the therapeutic efficacy of sterically stabilized nanoparticles by means of shedding, i.e. a loss of the coating after arrival at the target site. Such an 'unmasking' process may facilitate drug release and/or target cell interaction processes. This review presents an overview of the literature regarding different shedding strategies that have been investigated for the preparation of sterically stabilized nanoparticulates. Detach mechanisms and stimuli that have been used are described.
\end{abstract}

KEY WORDS: long-circulating nanoparticles; nanomedicines; poly(ethylene glycol); shedding; 'stealth' coatings.

\section{INTRODUCTION}

Nanoparticles, such as liposomes, polymeric micelles, lipoplexes and polyplexes have been extensively studied as targeted drug carrier systems over the past three decades. A wide variety of active agents can be incorporated into or complexed with these particles varying from low molecular weight drug molecules to macromolecules such as proteins

\footnotetext{
${ }^{1}$ Department of Pharmaceutics, Utrecht Institute for Pharmaceutical Sciences (UIPS), Utrecht University, Sorbonnelaan 16, 3584 CA, Utrecht, The Netherlands.

${ }^{2}$ To whom correspondence should be addressed. (e-mail: G.Storm@ pharm.uu.nl)
}

ABBREVIATIONS: BVEP, $(R)-1,2$-di- $O$ - $\left(1^{\prime} Z, 9^{\prime} Z\right.$-octadecadienyl)glyceryl-3-( $\omega$-methoxy-poly(ethylene glycolate); CHEMS, Cholesteryl hemisuccinate; $\mathrm{CerC}_{24}, \mathrm{C}_{20}, \mathrm{C}_{14}, \mathrm{C}_{8}$, Ceramides with acyl chains lengths of 24, 20,14, and 8 carbon atoms; c-TEM, Cryo transmission electron microscopy; DAG, Diacylglycerol = 1,2-diacylglycerol; DHCh, Hydrogenated cholesterol; DMA, 1,2 dimyristyloxypropyl-3-amine; DMG, 1,2-dimyristoylglycerol; DMPE, Dimyristoyl phosphatidylethanolamine $=1,2$ dimyristoyl-sn-glycero-3-phosphoethanolamine; DOG, 1,2dioleyl-rac-glycerol; DODAC, $N, N$-dioleyl- $N, N$-dimethylammonium chloride; DODAP, 1,2-dioleoyl-3-dimethylammonium-propane; DOPE, Dioleyl phosphatidylethanolamine $=1$,2-dioleoyl-sn-glycero-3-phosphatidylethanolamine; DOTAP, 1,2-dioleoyl-3-trimethylammonium-propane; DPG, 1,2-dipalmitoylglycerol; DPPE, Dipalmitoyl phosphatidylethanolamine = 1,2 dipalmitoyl-sn-glycero-3-phosphoethanolamine; DSA, 1,2 distearyloxypropyl-3-amine; DSG, 1,2-distearoylglycerol; DSPA, 1,2distearoyl-sn-glycerol-3-phosphatidic acid; DSPE, Distearoyl phospha- and nucleic acids (1). An important requirement to the systemic intravenous use of this targeted nanomedicine approach is the ability of the nanoparticles to circulate in the bloodstream for a prolonged period of time. To achieve this, often poly(ethylene glycol) (PEG) is used as a coating material. It is generally assumed that PEG creates a so-called 'steric stabilization' effect: the PEG molecules form a protective hydrophilic layer on the surface of the nano-

tidylethanolamine $=1,2$ distearoyl-sn-glycero-3-phosphoethanolamine; DTB, Dithiobenzyl carbamate; DTH, Dithio-3-hexanol; DTP, 3,3'dithiopropionate; DTT, Dithiothreitol; DXR, Doxorubicin; EGF, Epidermal growth factor; FRET, Fluorescence energy transfer; GFLG, Gly-Phe-Leu-Gly; Hz, Hydrazone; LDP, Lipid-DNA particles; MEND, Multifunctional envelope-type nanodevice; MMP, Matrix metallo proteinases; NLP, Nanoparticles with encapsulated plasmid DNA; ODN, Oligodeoxynucleotides; PC, Phosphatidylcholine $=1,2$ diacyl-sn-glycero-3-phosphocholine; PE, Phosphatidylethanolamine $=1,2$ diacyl-sn-glycero-3-phosphoethanolamine; PEG, Poly(ethylene glycol); PEI, Poly ethylene imine; PEOS, Poly(ethylene oxide sulfide); PFV, Programmable fusogenic vesicle; PHEG, Poly(hydroxyalkyl L-glutamine); PHEA, (Poly(hydroxyalkyl L-asparagine); PIC, Polyion complex; PLL, Poly-L-lysine; POD, $\mathrm{PEG}_{2000}$-diortho ester-distearoyl glycerol; polyDMAEMA, Poly(2-(dimethylamino)ethyl methacrylate); polyHPMA, Poly( $N$-(2-hydroxypropyl)methacrylamide); PPD, PEGpeptide-DOPE conjugate; PS, Phosphatidylserine; PSD, Poly(methacryloyl sulfadimethoxine); SAINT 12:0, 14:0, 16:0, 18:0, $\mathrm{N}$ methyl-4-alkylpyridinium chloride with alkyl chains lengths of 12,14 16, or 18 carbon atoms; SALP, Stabilized antisense-lipid particles; siRNA, Small interfering RNA; SPLP, Stabilized plasmid-lipid particles. 
particle that opposes interaction with blood components. As a result, the PEG coating reduces uptake by macrophages of the mononuclear phagocyte system (MPS) and provides relatively long plasma residence times (2). Until now, PEG is still the most widely used material for achieving steric stabilization. Nevertheless, successful attempts have been made to design alternative polymers, for example polymers based on poly(oxazoline) (3), polyvinyl alcohol (4), poly (glycerol) (5), poly- $N$-vinylpyrrolidone (6), poly[N-(2hydroxypropyl)methacrylamide] (7) and poly(amino acid)s (8) were investigated (for reviews, see $(1,9,10)$ ). For all these coating materials, prolonged circulation times of nanoparticles as compared to non-coated nanoparticles have been reported. It has to be realized, however, that steric stabilization is not desirable for all steps in the drug targeting process. The prolonged circulation time is needed to enable extravasation at sites with increased vascular permeability such as tumors and inflamed sites (enhanced permeability and retention (EPR) effect) (11). But after localizing in the pathological site, nanoparticles should deliver their contents in an efficient manner to achieve a sufficient therapeutic response. The polymer coating, however, may hinder drug release and target cell interaction and can therefore be an obstacle in the realization of the therapeutic response (1214). Attempts have been made to enhance the therapeutic efficacy of sterically stabilized nanoparticles by means of shedding, i.e. a loss of the coating after arrival at the target site. This 'unmasking' process may facilitate drug release and/or target cell interaction processes. The shedding concept provides a potential solution for several situations in which the polymer coating can have a negative effect on the delivery process (summarized in Fig. 1). Shedding can promote:

\section{Extracellular/Intracellular Release}

If, within the pathological site, extracellular release of the drug from the extravasated nanoparticle is sufficient, e.g. in the case of small molecules that easily pass target cell membranes, a delay in destabilization of the carrier due to its steric protection may limit the therapeutic availability of the drug within the target region. The shedding of the coating after arrival at the target site can lead to accelerated drug release. For example, if a non-bilayer forming lipid is retained in liposomes using a PEG-conjugate, the removal of the polymer coating would result in membrane destabilizing phase changes and consequently drug leakage (Fig. 1a). Obviously, besides for extracellular release, also for intracellular release shedding can be beneficial.

\section{Cellular Interaction}

In cases where the drug is not able to cross cell membranes (e.g. proteins, genes), extracellular release is not an option and it is required that the nanoparticles are internalized by the target cell to deliver the drug at the appropriate intracellular location. The polymer coating, however, interferes with the ability of the nanoparticles to interact with the target cells. Cellular interaction can be enhanced if a positive charge is present on the surface of the particles. Positively charged particles have been shown to bind to negatively charged plasma membranes with subsequent internalization via endocytosis (15). The polymer coating shields the charged surface during circulation and therefore prevents rapid clearance and aggregation due to electrostatic interactions with blood components. Shedding of the coating after entry of the target site would restore the possibility of interactions with the target cell membranes and thereby increase cellular uptake (Fig. 1c). As an alternative to introducing a positive charge, targeting ligands (e.g. antibodies, antibody fragments, and peptides) can be attached to the nanoparticle surface to induce internalization via specific receptors. Often, targeting ligands are being coupled to the terminal end of the PEG-chains. However, coupling the ligand to the distal end of the polymer chains can lead to an accelerated removal of the targeted particles from the circulation, especially at higher ligand densities (16). Moreover, the presence of targeting ligands may evoke immune responses prohibiting repeated dosing of the formulation (17). The shedding principle is a solution to avoid these problems. Ligands can be attached directly to the outer particle surface and are therefore shielded by the polymer coating during the circulation. Though the coating inhibits the interaction between the targeting ligand and its target receptor $(18,19)$, shedding of the polymer coating from the carrier would expose the ligand and make it available for receptor interaction (Fig. 1b).

\section{Cytosolic Delivery}

Once the particles are internalized by the target cells via endocytosis, they are often required to deliver their drug contents to the cytosol. Due to the presence of degradative enzymes and the relatively low $\mathrm{pH}$ present in the lysosomal compartment, however, the active substance may be prone to degradation before it reaches the cytosol. Moreover, the drug may be too hydrophilic and/or too large to efficiently pass the endo/lysosomal membranes. Both the degradation as well as restricted membrane transport can be a problem, particularly when delivering proteins or DNA. In these cases the cargo must be protected and able to escape from the endo/ lysosomal compartment. Endosomal escape can be mediated by fusogenic liposomes employing the lipid DOPE (20). These liposomes by themselves do not show the needed prolonged circulation times. If PEG is used as a sterically stabilizing component, the fusogenic potential and consequently the cytosolic delivery efficiency are unfortunately substantially reduced (13). Shedding of the coating would restore fusogenicity of the liposomes and allow for endosomal escape (Fig. 1d). Alternatively, to avoid inactivation of the drug in the endosomal compartment, it has been reported that cell-penetrating peptides, when attached to the surface of the carrier, mediate cellular uptake in an endocytosisindependent manner. Such peptides are shielded by the coating during the circulation and subsequent shedding of the coating at the target site exposes these peptides so internalization of the carrier can occur.

\section{Anti-PEG Immune Response After Administration of PEGylated Carriers Containing Nucleic Acids}

It has been reported that administration of nucleic acids such as antisense oligodeoxynucleotides (ODN), plasmid 


\section{Extracellular shedding}

a) extracellullar drug release

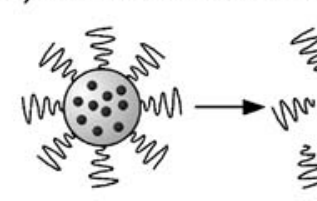<smiles>C1C[C@H]2CC[C@H]1C2</smiles>

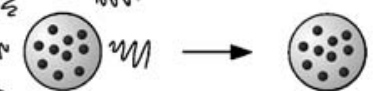

है $m$

b) exposure of a targeting ligand
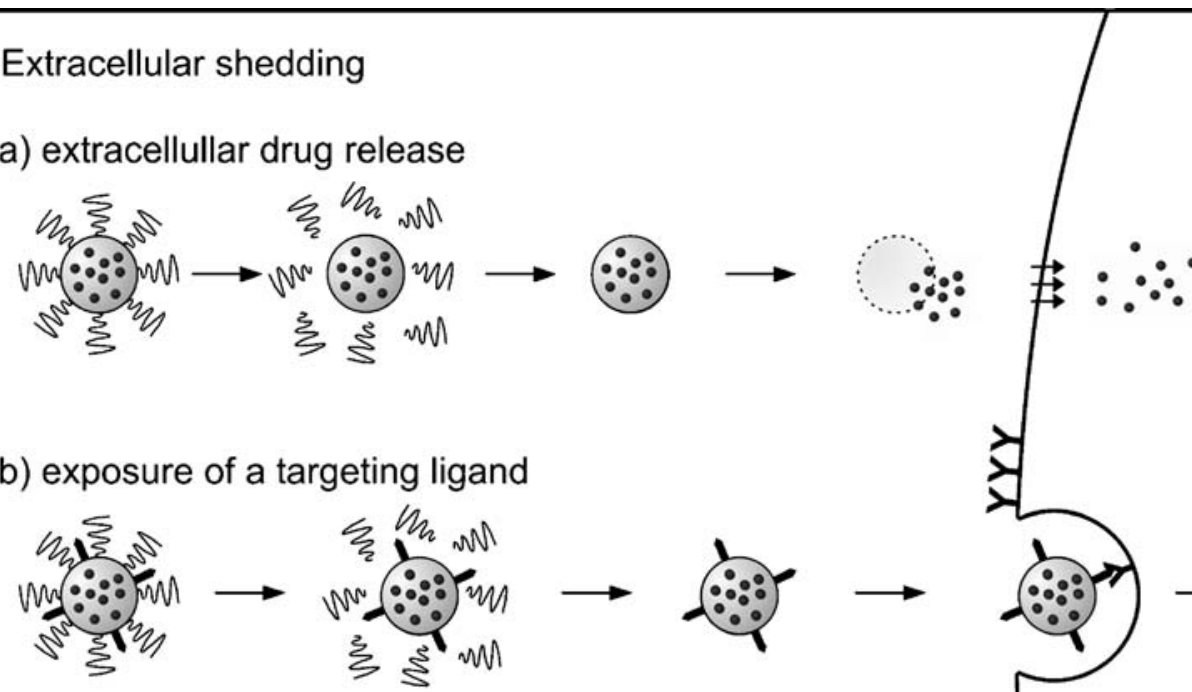

c) exposure of a positive charge
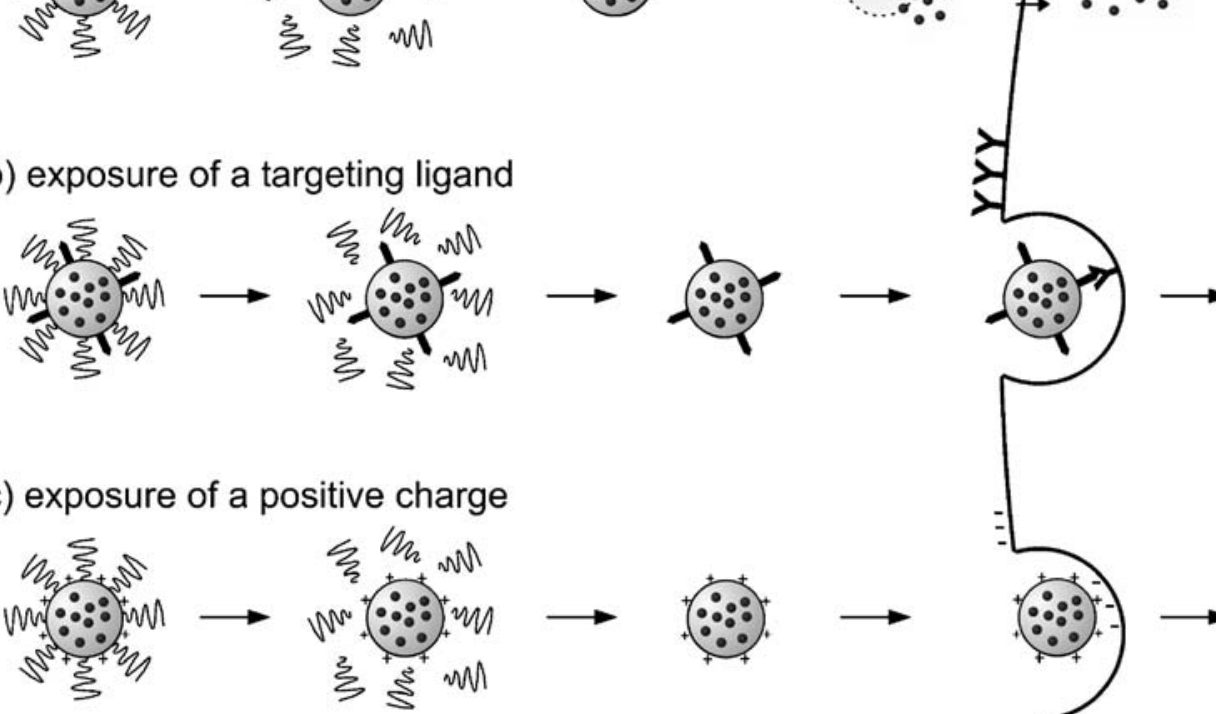

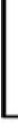

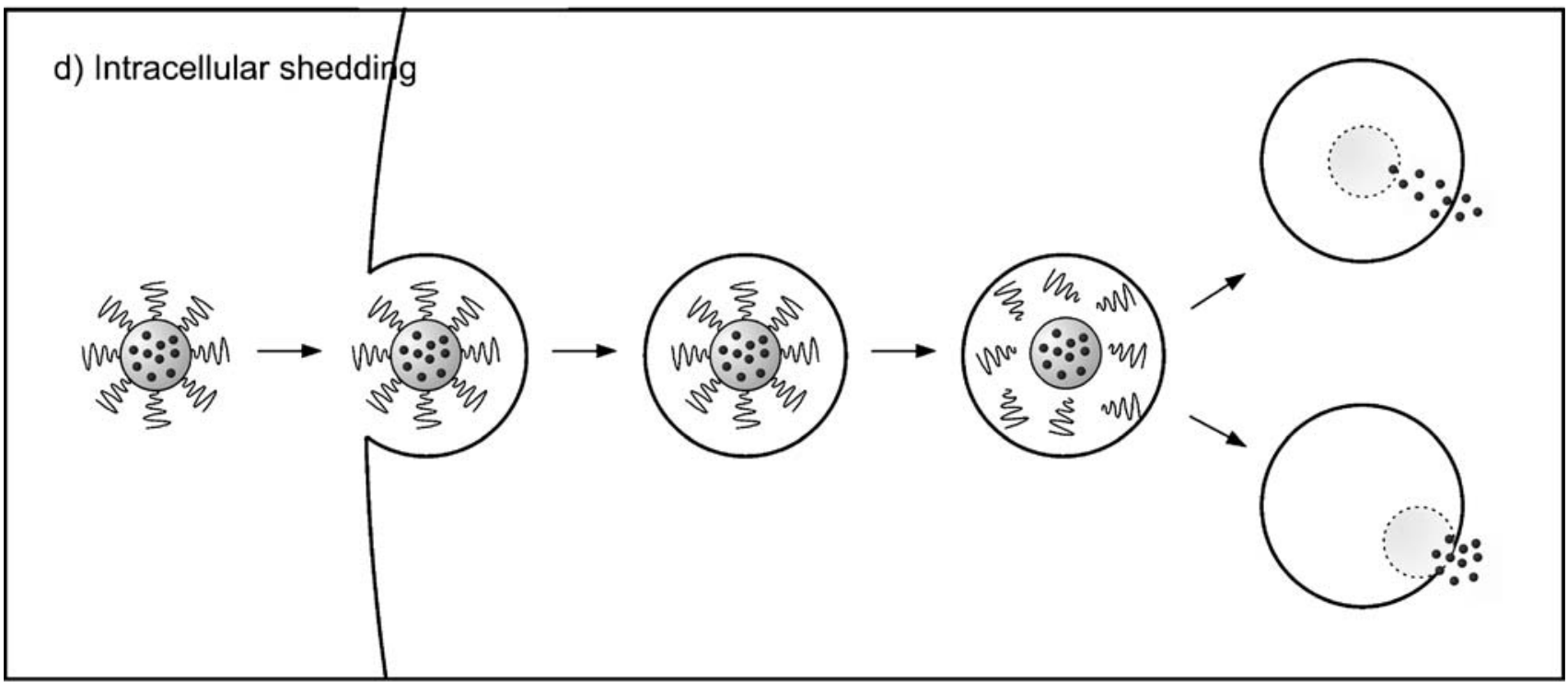

Fig. 1. Schematic representation of the different shedding applications following the localization of sterically stabilized nanoparticles at the target site. Top panel: extracellular shedding leading to: a extracellular release of the entrapped drug and subsequent uptake of the drug, $\mathbf{b}$ exposure of a targeting ligand and subsequent receptor-mediated internalization and intracellular drug release and $\mathbf{c}$ exposure of a positively charged surface and subsequent internalization and intracellular drug release. Bottom panel: d intracellular shedding after endocytosis and subsequent drug release events.

DNA or small interfering RNA (siRNA) formulated in PEGliposomes can raise an antibody-response against PEG, which may result in morbidity and rapid plasma elimination of liposomes administered with subsequent injections $(21,22)$. PEG is generally considered to be non-immunogenic (23). However, when PEG-lipids are used as coatings for nucleic acid-carrying liposomes, the nucleic acids can act as a potent adjuvant, resulting in an immune response against PEG. If the PEG-coating is gradually removed after administration, the immunogenicity of these nucleic acid containing particles is expected to be lower.

This review presents an overview of the literature regarding different shedding strategies that have been investigated for the preparation of sterically stabilized nano- 
particulates. Detach mechanisms and stimuli that have been used are described.

\section{SHEDDING APPROACHES}

\section{Shedding by Cleavage of a Linkage Between the Stabilizing Polymer and Its Anchor}

The coating polymer can be attached to a lipid anchor, which allows grafting to a lipidic surface, e.g. liposomal bilayers. A linker with a predetermined cleavage point between the polymer chains and the anchoring moiety can be introduced in this polymer-lipid conjugate. Chemical stimuli, such as the presence of low $\mathrm{pH}$ or reducing agents, and enzymatic stimuli, such as proteases, can induce cleavage of the linker. For an overview of shedding approaches using cleavable linkers see Table I.

\section{Low pH-Induced Shedding}

After entry into the target cell via receptor-mediated endocytosis, which is the uptake process for most particulate carriers, a lower $\mathrm{pH}$ is encountered in the endo/lysosomal compartment (24). Endosomes display a $\mathrm{pH}$ around 5.5-6.0 and lysosomes around 4.5. The extracellular $\mathrm{pH}$ within pathological sites such as tumors, inflammatory tissue and myocardial ischemia can also be lower than the physiological $\mathrm{pH}$ (25-27). If $\mathrm{pH}$-sensitive functional groups are applied as linkers between the polymer coating and its anchor, they may undergo protonation in the low $\mathrm{pH}$ environment, leading to hydrolysis of the sensitive bond and therefore to detachment of the polymer molecule. For nanoparticulate systems the diorthoester, the orthoester, the vinyl ether, the phosphoramidate, the hydrazone, and the $\beta$-thiopropionate linker have been applied as acid-sensitive linkers. An overview of the hydrolysis reactions involved is given in Fig. 2. Besides covalent bonds, linking of the coating to the carrier by electrostatic attraction, which are reduced or even abrogated at lower $\mathrm{pH}$, has been pursued.

The diorthoester linker. The diorthoester bond (Fig. 2a) is one of the most $\mathrm{pH}$-sensitive functional groups. Orthoesters are relatively stable under neutral conditions, but upon protonation they hydrolyze quickly due to the formation of a stabilized dialkoxy carbonium intermediate (28). The group of Szoka focused on the design of a sheddable coating which stabilizes the fusogenic DOPE in liposomes at neutral $\mathrm{pH}$. PEG was linked to distearoyl glycerol via a diorthoester bond $\left(\mathrm{PEG}_{2000}\right.$-diortho ester-distearoyl glycerol (POD) conjugate). Hydrolysis of this bond at the low endosomal $\mathrm{pH}$ was expected to result in destabilization of the DOPE-liposomes by promoting $L_{\alpha}-H_{\mathrm{II}}$ phase transition and thereby to mediate fusion with the endosomal membrane and contents release into the cytosol (29). While most of the POD conjugate remained intact over $3 \mathrm{~h}$ of incubation at $37^{\circ} \mathrm{C}$ and $\mathrm{pH}$ 7.4, complete degradation occurred within $1 \mathrm{~h}$ at $\mathrm{pH}$ 4 and 5. A fluorescence quenching assay was used to study the leakage and thereby destabilization of POD-liposomes. Liposomes with $10 \mathrm{~mol} \%$ of POD were stable in alkaline buffer for 2 weeks ( $\mathrm{pH}$ 8.5). At $\mathrm{pH}$ 5-6, resembling endosomal conditions, the liposomes collapsed within 10-100 min, showing extensive aggregation and contents leakage. Increasing amounts of POD on the liposome surface resulted in slower leakage kinetics (30). Kinetic studies in mice were performed with the POD/DOPE liposomes and revealed a halflife of $194 \mathrm{~min}$ (29). In comparison, PEG/DOPE liposomes had a half-life of $295 \mathrm{~min}$. Based on the results of the leakage and lipid mixing assays, a 'minimum surface shielding model' was proposed (31). Two phases of release were observed: an initial lag phase with only little leakage and a burst phase with extensive leakage. Upon $\mathrm{pH}$ decrease, hydrolysis of the diorthoester bond results in a reduction of the amount of POD molecules on the liposome surface (lag phase). Below a certain threshold level of surface-attached POD, intervesicular

Table I. Shedding Approach: Cleavage of a Linker Between the Stabilizing Polymer and its Anchor

\begin{tabular}{|c|c|c|c|c|c|c|}
\hline Stimulus & Linker & $\begin{array}{c}\text { Aimed } \\
\text { Shedding Site }\end{array}$ & $\begin{array}{c}\text { Type } \\
\text { nano-particle }\end{array}$ & References & $\begin{array}{l}\text { In vivo } \\
\text { Studies }\end{array}$ & (Ref) \\
\hline \multirow[t]{7}{*}{ Low $\mathrm{pH}$} & Diorthoester & $\begin{array}{l}\text { Extracellularly }^{a} \text {, } \\
\text { endosome }\end{array}$ & $\begin{array}{l}\text { Liposome, } \\
\text { NLP, SPLP }\end{array}$ & $(29-32)$ & + & $(29)^{b}$ \\
\hline & Orthoester & Extracellularly $^{a}$ & Lipoplex & (33) & - & \\
\hline & Vinylether & $\begin{array}{l}\text { Extracellularly }^{a} \\
\text { endosome }\end{array}$ & Liposome & $(34-36,38)$ & - & \\
\hline & Phosphoramidate & Endosome & ODN micelle & (39) & - & \\
\hline & Hydrazone & $\begin{array}{l}\text { Extracellularly }^{a} \text {, } \\
\text { endosome }\end{array}$ & $\begin{array}{l}\text { Micelles, liposomes, } \\
\text { polyplexes }\end{array}$ & $(40,41)$ & + & $(41)^{c}$ \\
\hline & $\beta$-thiopropionate & Endosome & $\begin{array}{l}\text { ODN micelle } \\
\text { siRNA micelle }\end{array}$ & $(42-44)$ & - & \\
\hline & Electrostatic & Endosome & Polyplex & $(45,46)$ & - & \\
\hline $\begin{array}{l}\text { Reducing } \\
\text { agents }\end{array}$ & Disulfide & $\begin{array}{l}\text { Extracellularly, } \\
\text { intracellularly } \\
\text { in endo/ lysosome } \\
\text { and cytosol }\end{array}$ & Liposome, polyplex & $(49-54)$ & + & $(50,51)^{b, d}$ \\
\hline Proteases & Peptide & $\begin{array}{l}\text { Endo/lysosome, } \\
\text { extracellularly }^{a}\end{array}$ & Liposome, MEND & $(51,59)$ & + & $(51,59)^{b, c}$ \\
\hline
\end{tabular}

\footnotetext{
${ }^{a}$ In tumor, inflamed or ischemic tissue

${ }^{b}$ Studies on pharmacokinetics and/or biodistribution

${ }^{c}$ Studies on gene expression

${ }^{d}$ Studies on therapeutic effects
} 
Table II. Shredding Approach: Spontaneous Extraction out of the Nanoparticles

\begin{tabular}{|c|c|c|c|c|}
\hline Exchangeable Anchor & Nano-particle type & References & In vivo Studies & (Ref) \\
\hline Phosphatidylethanolamine & Liposome, LDP & $(13,61-65)$ & + & $(61-63,65)^{a, c, d}$ \\
\hline Ceramide & $\begin{array}{l}\text { Liposome, SPLP, } \\
\text { PFV, lipoplex }\end{array}$ & $(66-75)$ & + & $(66,67,69,71,72)^{a, b}$ \\
\hline Diacylglycerol & Liposome, SPLP & $(21,22,76)$ & + & $(21,22,76)^{a, b}$ \\
\hline Dialkyloxypropylamine & SPLP & (77) & + & $(77)^{a, b}$ \\
\hline SAINT & Lipoplex & (78) & - & \\
\hline
\end{tabular}

${ }^{a}$ Studies on pharmacokinetics and/or biodistribution

${ }^{b}$ Studies on gene expression

${ }^{c}$ Studies on therapeutic effects

${ }^{d}$ Study on shedding in the circulation

mixing occurs and contents release is drastically intensified (burst phase). The advantage of the use of the POD conjugate is that rapid hydrolysis occurs at a mildly acidic $\mathrm{pH}$. This property makes the POD conjugate especially attractive for drug delivery situations in sites where the $\mathrm{pH}$ reduction is only one $\mathrm{pH}$ unit or less, such as in inflamed or malignant tissue.

Besides application for liposomes, the use of POD as a sterically-stabilizing coating has been studied for nonviral gene delivery vectors, in this particular case lipoplexes (32). Cellular uptake of these particles is mediated by electrostatic interaction of the positively charged lipoplexes with the negatively charged cell membranes. A cleavable PEGconjugate attached to the surface of these carriers should shield the positive charge in the circulation and thereby reduce unspecific interactions with blood components and increase the circulation half-life. On the other hand, the cleavable PEG coating should still allow successful delivery of the DNA and subsequent protein expression. To achieve this, stabilized plasmid-lipid particles (SPLP), composed of the cationic lipid 1,2-dioleyl-3-trimethylammonium-propane (DOTAP), DOPE, POD and plasmid DNA were designed. Shedding of the PEG-coating was assessed by studying the $\mathrm{pH}$-and time-dependent collapse of the particles using dynamic light scattering. While $\mathrm{pH}$-insensitive PEG-SPLP did not collapse at low $\mathrm{pH}$, POD-SPLP with $13 \mathrm{~mol} \%$ POD

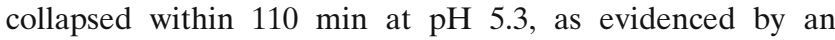
increase of the mean diameter of several hundreds of nanometers. PEG-SPLP and POD-SPLP were taken up by cultured CV-1 cells to a similar extent and in a similar punctuate pattern, but only the latter showed considerable gene transfection. This was likely a result of a faster endosomal escape mediated by shedding of the coating. POD nanoparticles with encapsulated plasmid DNA (referred to as NLP) showed superior transfection properties in CV-1 cells as compared to a $\mathrm{pH}$-insensitive control formulation (50-100 times higher transfection levels) (30). This was attributed to an enhanced endosomal escape of the DNA of these formulations, mediated by shedding of the coating. The authors claimed the POD formulation (POD with $\mathrm{PEG}_{2000}$ ) as the most optimal formulation when compared to formulations with diorthoester conjugates with a PEG molecular weight of 750 and 5,000, regarding small size, stability, cytotoxicity, and transfection efficiency.

The orthoester linker. Besides the diorthoester bond, also the orthoester bond (Fig. 2b) has been studied for its applicability to mediate shedding. Four PEG-orthoester lipid conjugates composed of either an octadecyl alkyl chain or a cholesteryl group (hydrophobic anchor) and a $\mathrm{PEG}_{5000}$ chain linked by either a six-membered or a five-membered orthoester ring structure were synthesized by Masson et al. (33). To assess the shedding potential, hydrolysis rates of these conjugates were determined. At room temperature and $\mathrm{pH} 7.5$, conjugates were stable for several days. Hydrolysis at $\mathrm{pH} 5$ was the fastest for the conjugate with the cholesteryl group and the six-membered ring orthoester and complete within $1 \mathrm{~h}$. Conjugates were used for the steric stabilization of lipoplexes based on a cationic lipopolyamine, DOPE, and plasmid DNA. Particle destabilization rates at lower $\mathrm{pH}$ were highest when the six-membered ring orthoester conjugate with the cholesteryl group was used. At pH 5 lipoplexes prepared with this conjugate aggregated within $30 \mathrm{~min}$. Transfection studies in vitro revealed a 25 -fold increase in transfection of HeLa cells in case of lipoplexes prepared with the most optimal PEG-orthoester lipid conjugate as compared to lipoplexes coated with non-cleavable PEG.

The vinyl ether linker. The vinyl ether linkage (Fig. 2c) was exploited by the group of Thompson to synthesize different vinyl ether-linked PEG-lipid conjugates and develop a shedding strategy for DOPE-based liposomes (34). Upon protonation of the vinyl ether $\beta$-carbon of this functional group, the double bond is cleaved releasing an alcohol and an aldehyde. PEG of two chain lengths $\left(\mathrm{PEG}_{2000}\right.$

Table III. Shredding Approach: Degradation of the Coating Material Itself

\begin{tabular}{|c|c|c|c|c|c|c|}
\hline Coating Material & Stimulus & Aimed Shedding Site & Nano-particle Type & References & In vivo Studies & (Ref) \\
\hline PEOS & $\begin{array}{l}\text { Reducing } \\
\text { agents }\end{array}$ & Cytosol & $\begin{array}{l}\text { Poly acrylic } \\
\text { acid-nanoparticle }\end{array}$ & (79) & - & \\
\hline Poly(amino acid)s & Proteases & $\begin{array}{l}\text { Endo/lysosome, } \\
\text { extracellularly }^{a}\end{array}$ & Liposome & $(80)$ & + & $(80)^{b}$ \\
\hline
\end{tabular}

\footnotetext{
${ }^{a}$ In tumor, inflamed or ischemic tissue

${ }^{b}$ Studies on pharmacokinetics and/or biodistribution
} 
a

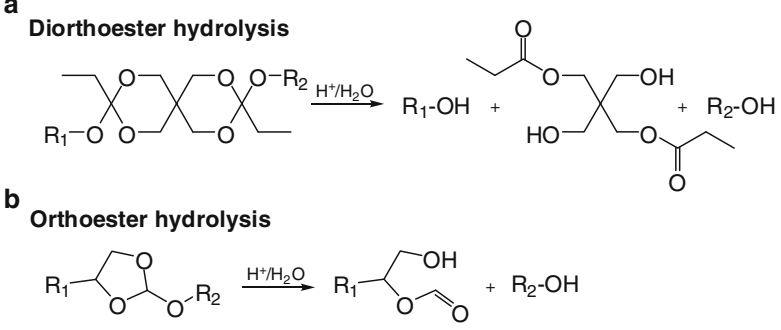

C Vinylether hydrolysis

$$
\mathrm{R}_{1}^{-} \mathrm{O} \smile-\mathrm{R}_{2} \stackrel{\mathrm{H}^{+} / \mathrm{H}_{2} \mathrm{O}}{\longrightarrow} \mathrm{R}_{1}-\mathrm{OH}+\mathrm{O} \smile \mathrm{R}_{2}
$$

d

Phosphoramidate hydrolysis
$\stackrel{\mathrm{R}_{1}-\mathrm{N}_{-}^{-}-\mathrm{P}_{\text {II }}^{\mathrm{O}}-\mathrm{O}-\mathrm{R}_{2} \stackrel{\mathrm{H}^{+} \mathrm{H}_{2} \mathrm{O}}{\longrightarrow}}{\longrightarrow} \mathrm{R}_{1} \mathrm{~N}-\mathrm{H}_{2}+\mathrm{H}_{2} \mathrm{PO}_{4}^{-}+\mathrm{R}_{2}^{-} \mathrm{OH}$

e Hydrazone hydrolysis

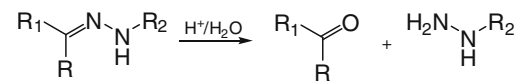

f $\beta$-Thiopropionate hydrolysis

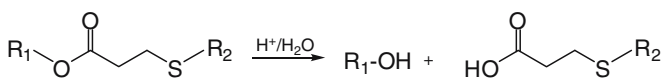

Fig. 2. Hydrolysis reactions relevant to acid-sensitive linkers used in sheddable coatings. $\mathrm{R}_{1}$ contains the hydrophilic part of the molecule (PEG), $\mathrm{R}_{2}$ contains the hydrophobic anchor, ODN or PLL, depending on the type of carrier.

and $\mathrm{PEG}_{5000}$ ) was coupled to 1,2-dioleyl-rac-glycerol (DOG) or DOPE as the lipid anchor, respectively. To evaluate shedding, the potential of these conjugates to promote low $\mathrm{pH}$-induced calcein release was investigated. Calcein was released from the liposomes within the time scale of hours in an acidic environment $(\mathrm{pH}<5)$. For example, the formulation with $5 \mathrm{~mol} \%$ of the $\mathrm{PEG}_{2000}$-vinyl ether-DOPE conjugate showed only $14 \%$ calcein release at $\mathrm{pH} 7.4$, whereas $95 \%$ of the calcein was released at $\mathrm{pH}$ 3.5. This nearly complete release, however, required $48 \mathrm{~h}$ of incubation. The rate of shedding increased in the case of the DOPE-anchor systems as the surface was negatively charged and therefore a higher proton concentration is present at the carrier surface. Furthermore, the vinyl ether bond orientation with respect to the membrane bilayer likely played a critical role, as shedding occurs more slowly if the sensitive linker is oriented closer to the hydrophobic acyl chain region.

The vinyl ether bond was also used to link $\mathrm{PEG}_{5000}$ to a hydrogenated cholesterol moiety (DHCh-MPEG 5000 ) (35). Hydrolysis of the conjugate was slow with the reaction still incomplete after 5 days at $\mathrm{pH} 4.5$. Studies on the interaction of fusogenic DOPE/DHCh-MPEG 5000 liposomes with endosome-like membranes suggested that even upon prolonged exposure to a low $\mathrm{pH}$, fusion with endosome-like membranes did not occur. The authors conclude from their findings that the slow cleavage rate of the conjugate is insufficient to make it applicable for shedding in vivo.
Improved properties of vinyl ether-linked PEG derivatives were demonstrated in a subsequent publication (36). A $\mathrm{PEG}_{5000}$-derivatized analogue of diplasmenylcholine with a vinyl ether linkage $((R)-1,2$-di- $O$-(1'Z,9' $Z$-octadecadienyl)glyceryl-3-( $\omega$-methoxy-poly(ethylene glycolate $))$, BVEP) was synthesized and utilized to stabilize DOPE liposomes (37). The shedding ability was assessed by analysis of the hydrolysis kinetics of BVEP, dye release from BVEP/DOPE liposomes and liposome fusion at low $\mathrm{pH}$ values. Eighty percent of the BVEP was hydrolyzed at $\mathrm{pH} 4$ after $60 \mathrm{~min}$. Liposomes containing $1-5 \mathrm{~mol} \%$ of the BVEP showed only little calcein release at neutral $\mathrm{pH}$ in buffer for up to one day. Also in $10 \%$ serum, these formulations were relatively stable (approx. 20\% calcein leakage over $20 \mathrm{~h}$ ) (38). The most optimal liposome formulation regarding dye retention at neutral $\mathrm{pH}$ and dye release at acidic $\mathrm{pH}$ (BVEP/DOPE 3:97) showed a collapse at $\mathrm{pH} 4.5$ within $3 \mathrm{~h}$ as shown by c-TEM. However, at this $\mathrm{pH}$ calcein release kinetics (78\% after $24 \mathrm{~h}$ ) and levels of membrane fusion ( $5 \%$ after $72 \mathrm{~h}$ ) were low (36). Several explanations for the slow kinetics were proposed: a generally slow hydrolysis rate, alterations of the microenvironment at the hydrolysis site (e.g. a less acidic $\mathrm{pH}$ than in the surrounding solution), and an inhibition of the DOPE phase transition caused by e.g. retention of hydrolyzed PEG on the liposome surface. The authors conclude that contents release and membrane fusion were not rapid enough and must be increased for application in vivo.

The phosphoramidate linker. The acid-induced shedding approach was also applied to DNA/PEG hybrid micelles for delivering ODN, which are able to bind to cytoplasmic mRNA to block specific gene expression (39). Shedding of the stabilizing PEG layer can be advantageous as PEG might sterically hinder interaction of ODN with the target RNA after ODN-PEG have been released into the cytosol. Jeong et al. used an acid-cleavable phosphoramidate group (Fig. 2d) to covalently link the ODN to PEG resulting in a diblock copolymer-like structure. At a $\mathrm{pH}$ of 4.7 , almost quantitative linkage hydrolysis was achieved within $5 \mathrm{~h}$. The negatively charged ODN-PEG conjugate was complexed with the cationic fusogenic peptide KALA to increase endosomal escape. This resulted in polyelectrolyte complex micelles with the PEG molecules forming the hydrophilic corona. A comparison with a formulation bearing PEG with a noncleavable linker was not performed. Thus, although the results on the delivery and antisense effect found in this study were encouraging, they provide no evidence for a benefit of the PEG shedding.

The hydrazone linker. Another linker that is sensitive to low $\mathrm{pH}$ and therefore of potential value for use in sterically stabilized nanoparticle systems is the hydrazone bond (Fig. 2e). Sawant et al. designed micelles and liposomes with a sheddable coating using the $\mathrm{pH}$-sensitive hydrazone linker to couple PEG to phosphatidylethanolamine (PEG-Hz-PE) (40). The stability of PEG-Hz-PE micelles was assessed by size exclusion chromatography. The micelles were intact after 20 min of incubation at room temperature at $\mathrm{pH} 10$, whereas at $\mathrm{pH} 7$ the amount of micelles was reduced to $56 \%$ and at pH 5 only $3 \%$ of the micelles were recovered. PEG-Hz-PE micelles composed of PEG-PE (40 mol\%) and PEG-Hz-PE (54 $\mathrm{mol} \%$ ) were prepared. Biotin was included as a model targeting ligand to be exposed after shedding. Biotin binding 
was assessed on a NeutrAvidin affinity column. While at $\mathrm{pH}$ 8 only $15 \%$ of the micelles were retained on the column, $75 \%$ of the micelles were retained after 15 min incubation at $\mathrm{pH} 5$, due to exposure of the biotin ligand after shedding of the PEG-coating. PEG-Hz-PE carriers were tested for association and internalization by $3 \mathrm{~T} 3$ cells (micelles) and U-87 MG cells (liposomes) using fluorescence microscopy. For these experiments, cell penetrating TAT moieties were used instead of biotin groups. Micelles with $5 \mathrm{~mol} \%$ of the TAT peptide were only marginally associated with cells when kept at $\mathrm{pH} 8$, however association was clearly enhanced when micelles were preincubated for 20-30 min at $\mathrm{pH} 5$ before adding them to cells. For liposomes with $9 \mathrm{~mol} \%$ of the cleavable PEG-Hz-PE, association with cells were at levels comparable to the non-coated liposomes after preincubation for $20 \mathrm{~min}$ at $\mathrm{pH} \mathrm{5}$, indicating that the TAT function could mediate association after shedding.

Walker and colleagues have reported on the synthesis of several different poly-L-lysine (PLL)-PEG conjugates linked via hydrazone bonds for non-viral gene delivery systems (41). The two most promising candidates showed hydrolysis halflives of 30 min (acylhydrazone-linked PEG-conjugate) and 1.5 h (2-pyridylhydrazone-linked PEG-conjugate) at $\mathrm{pH} 7.4$ and $37^{\circ} \mathrm{C}$, but only $10 \%$ of the conjugates remained intact after $10 \mathrm{~min}$ at $\mathrm{pH} 5$ and $37^{\circ} \mathrm{C}$. Shedding was assessed by measuring changes in zeta potential and particle size of the polyplexes. Polyplexes prepared without PEG-conjugates aggregated after $1 \mathrm{~h}$ at $37^{\circ} \mathrm{C}$ in the presence of salt. Polyplexes with the 2-pyridylhydrazone-linked and the acylhydrazone-linked conjugates were stable for $5 \mathrm{~h}$ and $30 \mathrm{~min}$ of incubation at $\mathrm{pH} 7.4$ and $37^{\circ} \mathrm{C}$, respectively. However, at $\mathrm{pH} 5$, within two hours (2-pyridylhydrazone-linked conjugate) and 30 min (acylhydrazone-linked conjugate), a maximum in surface charge and aggregation of polyplexes was reached. Transfection studies with poly (ethylene imine) (PEI)-based polyplexes shielded with hydrolysable PEGconjugates showed that transfection levels in different cell types were similar to those obtained with non-shielded polyplexes and were approximately $40-100$ fold higher than for a polyplex formulation with a non-hydrolysable PEGPLL conjugate. The authors assume that an improved endosomal escape of the DNA after shedding of the PEG-coating is responsible for improved transfection activity. In a subcutaneous mouse tumor model, epidermal growth factor receptor (EGF) targeted polyplexes were used for transfection after intravenous administration. Polyplexes prepared with the 2-pyridylhydrazone-linked conjugate showed more than one order of magnitude higher luciferase expression in the tumor when compared to polyplexes with a non-hydrolysable PEG-PLL conjugate. The authors suggest that shedding increases the intracellular trafficking efficiency of the polyplexes by increasing for example endosomal escape.

The $\beta$-thiopropionate linker. The group of Kataoka investigated a $\beta$-thiopropionate linker (Fig. 2f) as acid-labile ester group to link antisense ODN to PEG and form polyion complex (PIC) micelles with these conjugates together with linear PEI (42). At pH 7.4 almost no cleavage of the linker was observed, however, $97 \%$ was cleaved after $24 \mathrm{~h}$ at $\mathrm{pH}$ 5.5. Size exclusion chromatography showed that at $\mathrm{pH} 5.5$ the PIC micelle peak completely disappeared after six hours. Precipitation was observed in the samples. Micelles with the $\beta$-thiopropionate linker had an increased antisense effect as compared to micelles with an acid-insensitive linker (65\% vs. $27 \%$ inhibition of luciferase gene expression) (43). The authors conclude that the cleavage of the acid-labile linker in the endosomes is an important requirement for the release of the free ODN into the cytosol and subsequent antisense effect. Besides ODN-mediated effects, successful gene silencing was achieved with PIC micelles prepared by coupling siRNA to PEG via the $\beta$-thiopropionate linker and complexation with PLL (44).

Linking via electrostatic interactions. In addition to covalent bonds, also non-covalent bonds have been exploited for low-pH induced shedding. Finsinger and colleagues designed PEG-peptide conjugates, containing negatively charged glutamic acid residues, which bind electrostatically to positively charged PEI-DNA complexes (45). These conjugates reduced opsonization as compared to non-coated polyplexes and were designed to dissociate from the PEIDNA complex at the low $\mathrm{pH}$ in endosomes due to protonation of the negatively charged peptides. They were equally effective in in vitro gene delivery when compared to non-coated polyplexes. A similar approach was pursued by Auguste et al. (46). Different PEG-polycation copolymers were synthesized and adsorbed onto liposomes containing the $\mathrm{pH}$-sensitive lipid 1,2-dioleoyl-3-dimethylammoniumpropane (DODAP), which is neutral at $\mathrm{pH} 7.4$ and positively charged at $\mathrm{pH}$ 5.5. Lowering the $\mathrm{pH}$ from 7.4 to 5.5 was expected to result in a positively charged liposome surface and consequently desorption of the PEG-polycation copolymers from the liposome surface. Indeed, copolymers with PEG $_{5000}$-pDMAEMA showed decreased association constants upon lowering the $\mathrm{pH}$ from 7.4 to 5.5.

Sethuraman et al. designed poly(methacryloyl sulfadimethoxine)-block-PEG (PSD-b-PEG) copolymers, which were adsorbed onto a positively charged DNA/PEI complex at neutral $\mathrm{pH}$ due to the negatively charged PSD (47). Size and zeta potential analysis of DNA/PEI/PEG-b-PSD polyplexes showed changes at a $\mathrm{pH}$ around 6.6, indicating neutralization of PSD and detaching of the PEG-b-PSD copolymer from the complex surface. Cell viability experiments showed that polyplexes were non-toxic at $\mathrm{pH}$ 7.4, but that cell viability was decreased to $20 \%$ at $\mathrm{pH}$ 6.6. Transfection studies showed a 10-fold increase in transfection when altering the $\mathrm{pH}$ from 7.4 to 6.6. The authors noted that a disadvantage of this system is that the detached copolymers are nondegradable and the aggregates formed may be toxic.

Acid-triggered shedding represents a straightforward approach. Among the acid-releasable coatings investigated so far, the diorthoester and the hydrazone-linked coatings are probably the most advanced. The diorthoester linkage has fast hydrolysis kinetics and a relatively mild $\mathrm{pH}$ decrease already induces shedding (29). That makes the system most attractive for extracellular shedding in tumors and inflammatory tissue.

\section{Reduction-Induced Shedding}

Bioconjugation using reduction-sensitive linkers has been a popular approach in the design of drug delivery systems (for a review see (48)). The disulfide bond (-S-S-) is 
reversible, but relatively stable in plasma. This bond is formed by oxidation of two sulfhydryl groups and can be cleaved by reducing agents. Extracellularly, due to the oxidizing environment, formation or maintenance of the disulfide bond is favored. The high cytosolic concentration of sulfhydryl group-carrying molecules (e.g. glutathion) creates a reductive environment and cleavage of the disulfide bond occurs relatively quickly under these conditions. Moreover, reduction of these bonds can take place at the cell surface catalyzed by cell surface-associated redox enzymes and in the endo/lysosomal compartment due to the presence of e.g. cysteine and redox enzymes. Therefore, for particulate carriers bearing a sheddable coating that responds to changes in the redox potential, improved cellular interaction, enhanced endosomal escape, and/or cytosolic destabilization of the carrier can be envisaged. Molecular structures of the conjugates used as coatings to achieve reductioninduced shedding are summarized in Fig. 3.

Zalipsky and colleagues stabilized DOPE liposomes by incorporation of 3-6 mol\% of a disulfide-linked PEG conjugate. PEG was coupled to distearoyl phosphatidylethanolamine (DSPE) via 3,3'-dithiopropionate (DTP) as linking moiety (PEG-DTP-DSPE, Fig. 3a) (49). Shedding was evaluated by dye release and lipid mixing studies. No leakage of liposome contents occurred upon incubation in buffer $(\mathrm{pH}$ 7.2) or serum at $37^{\circ} \mathrm{C}$ for $36 \mathrm{~h}$. Yet, in the presence of $10 \mathrm{mM}$ dithiothreitol (DTT), a complete release of the encapsulated dye and lipid mixing was observed $(50 \%$ release and lipid mixing within approximately one hour), likely as a result of shedding and subsequent liposome destabilization. DOPE/ CHEMS/PEG-DTP-DSPE liposomes (cholesteryl hemisuccinate (CHEMS) was included to achieve $\mathrm{pH}$ sensitivity), retained an encapsulated dye in buffer of $\mathrm{pH} 5.5$ at $37^{\circ} \mathrm{C}$ during at least one day. When DTT or cell-free extracts to mimic intracellular environments were added, liposomes released their contents within a time-scale of hours $(49,50)$. After detachment of the PEG chains, the phospholipid derivative 3-mercaptopropionyl-DSPE, was retained on the liposome surface, which might hinder contact between bilayers of the fusogenic liposomes and therefore be responsible for additional stabilization (49). In vitro toxicity and nuclear accumulation studies of doxorubicin (DXR) loaded liposomes showed that formulations with the cleavable PEG conjugate were not more cytotoxic than the formulation with the non-cleavable PEG conjugate. Nevertheless, a faster nuclear accumulation of DXR over a period of $12 \mathrm{~h}$ was seen for the PEG-DTP-DSPE containing formulation (50). Survival studies performed in a murine model of B-cell

a

\section{PEG-DTP-DSPE}

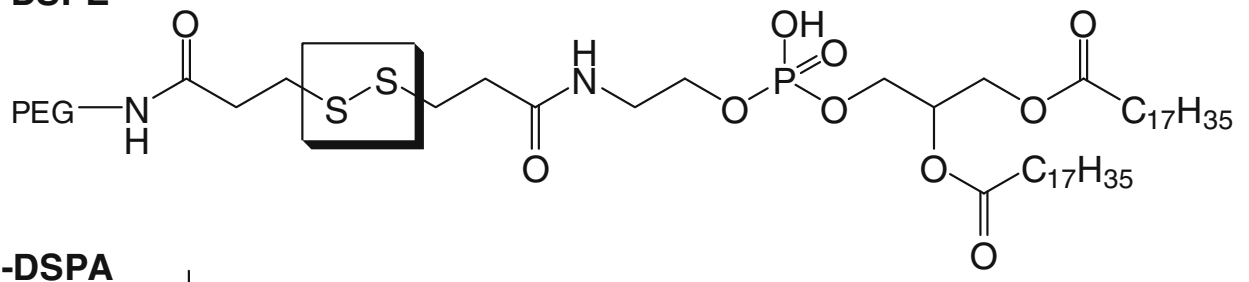

b

\section{PEG-DTH-DSPA}

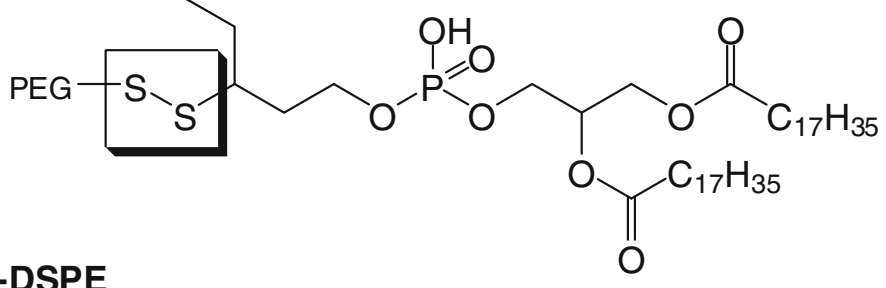

\section{PEG-DTB-DSPE}

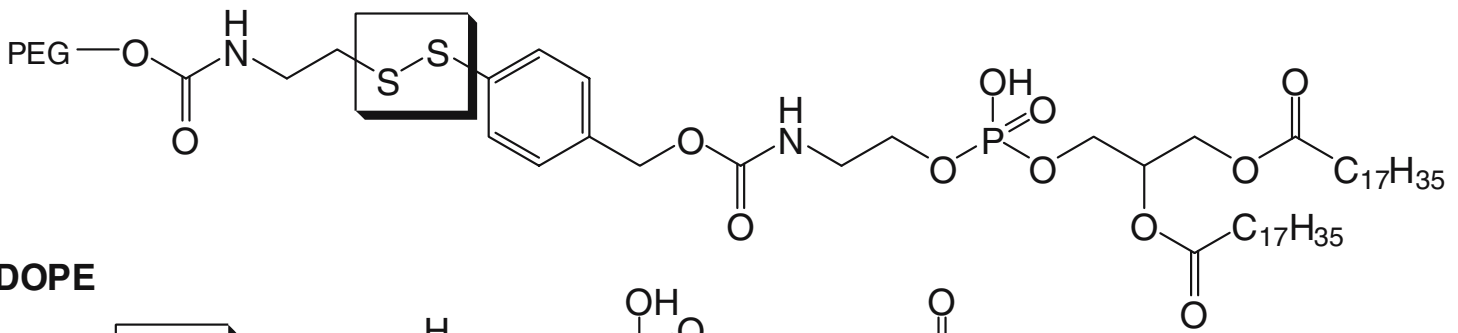

PEG-S-S-DOPE<smiles>CCCCCCCC(=O)OCC(COP(=O)(O)OCCNC(=O)CCSCC#P)OC(=O)C(C)(C)C</smiles>

Fig. 3. Reduction-sensitive PEG-S-S-lipid conjugates. 
lymphoma demonstrated an improved therapeutic efficacy of doxorubicin encapsulated in anti CD19-targeted DOPE/ CHEMS/PEG-DTP-DSPE liposomes as compared to the non-cleavable formulation at the same doxorubicin dose (1.5 times increased life span in mice). Surprisingly, DOPEbased liposomes stabilized with up to $8 \mathrm{~mol} \%$ of the cleavable PEG conjugate did not yield improvement of circulation times in mice when compared to non-coated liposomes, possibly caused by rapid cleavage of the disulfide bridges in the circulation.

To avoid this rapid cleavage, a dithio-3-hexanol linker was evaluated to link PEG to 1,2-distearoyl-sn-glycerol-3phosphatidic acid (PEG-DTH-DSPA, Fig. 3b) (51). The attack of the DTH linker is sterically hindered by a propyl group, which was expected to result in a higher stability of the disulfide bond. And indeed, PEG-DTH-DSPA containing liposomes showed similarly prolonged circulation times as compared to liposomes coated with non-cleavable PEG. Studies on release of doxorubicin in the presence of $5 \mathrm{mM}$ DTT showed that all PEG-coated formulations released the drug relatively slowly, in a time scale of hours. An exception was the formulation with $15 \mathrm{~mol} \%$ of PEG-DTH-DSPA, which showed enhanced leakage as compared to the noncleavable formulation at $\mathrm{pH} 7.4$, likely mediated by shedding of the PEG-coating: approximately $90 \%$ of the liposomal DXR was released over $24 \mathrm{~h}$ of incubation in case of the cleavable formulation versus less than $25 \%$ release in the case of the non-cleavable one.

To improve the reductive shedding approach, an alternative class of reduction-sensitive linkers to couple PEG to DSPE was designed (Fig. 3c) (52). Dithiobenzyl carbamate linkers (DTB, in $o$ - and $p$ - configurations) were expected to be cleaved under mild thiolytic conditions due to their mixed aliphatic and aromatic nature. Furthermore, as an amine endgroup was generated after cleavage rather than the bulky mercaptopropionyl derivative in case of the DTP linker, an improved restoration of fusogenicity after shedding of the coating was expected. The conjugates were susceptible to cleavage in the time scale of minutes in an already mild reductive environment ( $150 \mu \mathrm{M}$ cysteine) as shown by HPLC analysis, even when attached to a liposome surface. When 3 mol\% of PEG-DTB-DSPE was incorporated into DOPE liposomes, this formulation showed no contents release in buffer at $\mathrm{pH} 7.2$ and $37^{\circ} \mathrm{C}$ within at least $60 \mathrm{~min}$ of incubation, but did release an encapsulated dye within 60 min when mild reducing conditions were applied. After prolonged exposure to a low concentration of $15 \mu \mathrm{M}$ cysteine, which is the average concentration found in plasma, a slight content release was also observed (10-20\% within 60 $\mathrm{min}$ ), indicating that the conjugates were possibly even too trigger-sensitive and that drug release may already take place during circulation.

A different shedding approach was pursued by Maeda et al. (53). To avoid drug inactivation in the endo/lysosomal compartment, fusogenic liposomes with a reduction-sensitive sheddable PEG-coating and R8 cell-penetrating peptide coupled to the liposome surface were designed. Shedding of part of the PEG molecules was proposed to occur in the vicinity of the cell surface and should lead to exposure of the cell-penetrating R8 peptide, which would promote uptake by plasma membrane translocation. Further removal of the
PEG-coating in the cytosol was proposed to lead to destabilization of liposomes and consequently drug release. A PEG-S-S-DOPE conjugate (Fig. 3d) was synthesized and incorporated into calcein containing phosphatidylcholine (PC)/DOPE/CHEMS/R8 liposomes at a level of $5 \mathrm{~mol} \%$. In the absence of a reducing agent, calcein was not released within $24 \mathrm{~h}$. In the presence of $30 \mathrm{mM}$ cysteine, only approximately $10 \%$ release was observed after $24 \mathrm{~h}$. With $240 \mathrm{mM}$ cysteine a maximum release of $30 \%$ was reached after $7 \mathrm{~h}$, with $10 \mathrm{mM}$ glutathione release was fast, but incomplete (approximately $70 \%$ release within $4 \mathrm{~h}$ ). Internalization of calcein-loaded liposomes was studied using A431 cells. Liposomes with the cleavable PEG-coating were internalized in a cysteine concentration-dependent manner. Relatively low cysteine concentrations of $\leq 30 \mathrm{mM}$, for which no calcein release was observed, resulted in internalization of the carrier. Furthermore, it was demonstrated that cysteine was essential for plasmid delivery and transfection. The authors conclude that at mild reducing conditions, which may be encountered at the potential target sites, part of the PEG molecules are cleaved off with display of the R8 peptide as a result. After arrival in the cytosol, destabilization of the carrier can occur at the higher concentrations of reducing agents encountered.

Results of Carlisle et al. show the first successful reduction-induced shedding approach for polyplexes (54). DNA/PEI complexes with thiol groups were surface-coated with pyridyldisulfanyl groups-containing polyHPMA as a 'stealth' coating, generating a disulfide linker between PEI and polyHPMA. Polyplexes did not release DNA upon incubation with a polyanion, indicating sufficient stabilization. In the presence of 20 or $40 \mathrm{mM}$ DTT, however, DNA was released after 2 hrs of incubation. Transfection activities of polyplexes with the reducible linker were 40-fold higher than those obtained with polyplexes with a non-cleavable linker. Increasing cytosolic reducing activity by co-delivery of glutathion monoethyl ester resulted in increased transfection levels, whereas co-delivery of a glutathion-inhibitor decreased transfection levels, demonstrating a clear role for shedding in this approach. The applicability of using polyHPMA to prolong polyplex circulation times in vivo, however, remains to be evaluated.

Shedding triggered by high redox-potentials in tissues is an appealing strategy, as demonstrated by the various research groups (49-54). However, often high concentrations of reductive agents are required which are not present in physiological/pathological environments (49). Nanoparticles are mainly taken up by endocytosis, however, disulfide reduction is a slow process under the acidic conditions encountered in the endo/lysosomal compartment (55). The cytosol is the location with the highest concentration of reducing agents the carrier can encounter and therefore the best shedding site. Particles which are taken up by endocytosis, however, might not reach the cytosol and therefore the applicability of these systems might be limited.

\section{Proteolysis-Induced Shedding}

Cleavage of a peptide linker located between the coating polymer and its anchor requires the presence of proteolytic enzymes as encountered e.g. in the endo/lysosomal compart- 
ment. In these organelles, high concentrations of various proteases are associated with a high protein and peptide turnover. Furthermore, proteolytic enzymes, e.g. lysozymes and cathepsins, are also present extracellularly in pathological sites that involve tissue-remodeling states such as inflammatory and malignant areas (56-58).

Zhang et al. investigated the feasibility of proteolysisinduced shedding (51). A small peptide (Gly-Phe-Leu-Gly), a substrate for e.g. cathepsin $\mathrm{B}$, was used to conjugate $\mathrm{PEG}$ with DSPE (PEG-GFLG-DSPE). DOPE/CHEMS liposomes prepared with $15 \mathrm{~mol} \%$ of the cleavable PEG conjugate showed prolonged circulation times. However, release of doxorubicin from these liposomes at $\mathrm{pH} 5.5$ was not improved in the presence of cathepsin B when compared to liposomes incubated without cathepsin B. This relatively disappointing result was attributed to slow cleavage kinetics and/or increased stability due to the retention of lipids with peptidylaminoethanol groups in the bilayer.

Hatakeyama et al. designed a PEG-peptide-DOPE conjugate (PPD) to stabilize DNA polycation complexes based on DOTAP, DOPE and cholesterol (referred to as multifunctional envelope-type nanodevice, MEND) during circulation. Cellular interaction was aimed to be facilitated by means of shedding of the PEG-coating after cleavage of the peptide linker by matrix metallo proteinases (MMP) which are secreted by tumor cells into the extracellular space (59). The PPD conjugates were cleaved in the presence of MMP-2 (14 and $56 \mathrm{nM}$ ) as confirmed by MALDI-ToF mass spectrometry analysis. When attached to liposomes, an increase in liposome size was observed after $24 \mathrm{hrs}$ of incubation with MMP-2, indicating $\mathrm{H}_{\mathrm{II}}$-transition of DOPE. The transfection efficiency of PPD-MEND was analyzed using a MPP expressing cell line (HT1080 fibrosarcoma cells) and a non-MMP expressing cell line (HEK293 cells). As an example, the transfection efficiency of PPD-MEND with 5\% MEND was 35-fold higher in HT1080 cells than that of MEND with a non-cleavable PEG. Circulation time studies in mice revealed that PPD prolonged circulation time of MEND significantly; however, circulation times of MEND with a non-cleavable PEG were superior. Tumor accumulation of PPD-MEND was increased when compared to noncoated MEND. In vivo transfection studies in tumor tissue after i.v. administration showed a superior transfection effect of PPD-MEND when compared to PEG-MEND. This study clearly shows promise for the applicability of systems with a proteolytically cleavable linker, exploiting enzymes present within the (patho-)physiologically environment.

\section{Shedding by Spontaneous Extraction Out of the Nanoparticles}

Conjugates of lipids and hydrophilic polymers are generally able to diffuse out of membranes depending on the strength of the anchorage (60). Silvius and Zuckerman investigated the transfer of several phospholipid-polymer conjugates between phospholipid vesicles using fluorescence resonance energy transfer (FRET). Their results suggest that hydrophilic polymers grafted to lipid bilayers by hydrophobic anchors with 18 carbons or less may generally be able to transfer between membranes, with half lives up to several tens of hours, depending on the anchor chain composition. The strength of the interaction between the anchor moiety and the membrane lipids determines the rate and extent of extraction.

Five types of exchangeable PEG-lipid conjugates have been studied as sheddable 'stealth' coatings on liposomes or lipoplexes (Fig. 4): PEG-phosphatidylethanolamine conjugates, PEG-ceramide conjugates, PEG-diacylglycerol conjugates, PEG-dialkyloxypropylamine conjugates and PEGSAINT conjugates.

\section{PEG-Phosphatidylethanolamine Conjugates}

The group of Madden investigated the transfer of PEGdiacyl-sn-glycero-3-phosphoethanolamine (PEG-PE, Fig. 4a) conjugates out of large unilamellar, fusogenic DOPE/PS liposomes to neutral acceptor 'sink' liposomes (13). Calcium-induced fusogenic activity of the DOPE/PS liposomes was inhibited by low amounts of PEG-lipids, but completely restored upon extraction of the PEG-lipids. The fusion rate was dependent on the acyl chain length (DMPE $\left(\mathrm{C}_{14}\right)>$ DPPE $\left.\left(\mathrm{C}_{16}\right)>\operatorname{DSPE}\left(\mathrm{C}_{18}\right)\right)$ and the degree of saturation of the anchoring acyl chain (unsaturated $>$ saturated).

Programmable fusogenic vesicles (PFV) that exhibit time-dependent destabilization were designed to achieve disease-site selective leakage of the incorporated drug (61). PFV were composed of the non-bilayer forming lipid DOPE, cholesterol, the cationic lipid $N, N$-dioleyl- $N, N$-dimethylammonium chloride (DODAC) to promote cell binding and 10 $\mathrm{mol} \%$ of PEG-PE lipids with different acyl chain lengths (DMPE, DPPE and DSPE) to shield the positive charge and to stabilize the bilayer conformation. Circulation time studies in mice showed that the PEG-PE formulation with the shortest acyl chain (DMPE) were rapidly eliminated from the circulation, in agreement with a fast extraction of the conjugate, while the formulations with the DPPE and DSPE anchor were circulating considerably longer (50\% present in the circulation at $4 \mathrm{~h}$ and $24 \mathrm{~h}$, respectively). Studies in a human colon carcinoma xenograft model showed, that PFV prepared with PEG-DSPE and containing the anticancer drug mitoxantrone had a higher antitumor activity after intravenous administration as compared to the PEG-DMPE containing formulation, likely due to superior circulation kinetics of the former type resulting in higher drug levels in tumor tissue.

An assay based on biotin-streptavidin interaction was applied by the group of Bally to study the potential of exchangeable PEG-lipids to temporarily shield targeting ligands which were attached to the liposome surface (62). A functional, indirect assay was used to assess the generation of a surface shield on biotinylated acceptor liposomes. Liposomes prepared with PEG-PE conjugates with different acyl chain lengths were used as PEG-PE donor liposomes. Transfer of the PEG conjugates to the acceptor liposomes was studied in a biotin binding assay using streptavidin (SA)coated magnetic particles. Whereas PEG-DSPE was not able to transfer to the acceptor liposome population as reflected by unaltered binding of the acceptor liposomes to SA, PEGDMPE was transferred significantly at the time-scale of minutes at $37^{\circ} \mathrm{C}$. To measure PEG-lipid conjugate extraction in vivo, biotinylated liposomes shielded with different PEG- 
a<smiles>CCCCCCCCCCCCCCCCCCCCCCCCC(=O)OC[C@H](COP(=O)([O-])OCCNC(=O)OCCC(C)(C)OC)OC(=O)CCCCCCCCC</smiles>

PEG-DSPE

b

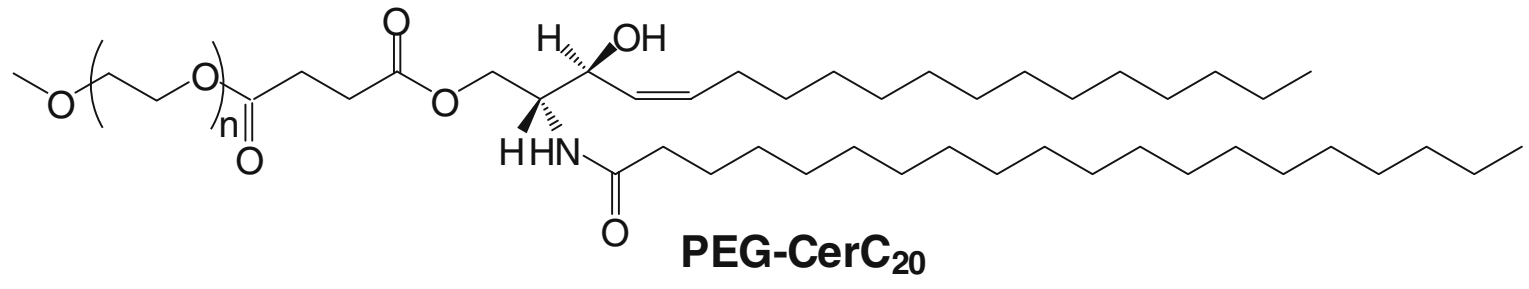

C<smiles>CCCCCCCCCCCCCCCCCCCCCCCCC(=O)OC[C@H](COC(=O)CCC(C)(OC)OCC(C)(C)OC)OC(=O)CCCCCCCC</smiles>

PEG-DSG

d<smiles>CCCCCCCCCCCCCCCCCCOCC(CNC(=O)C(C)OCC(C)(C)OC)OCCCCCCCCCCCC</smiles>

PEG-C-DSA

e

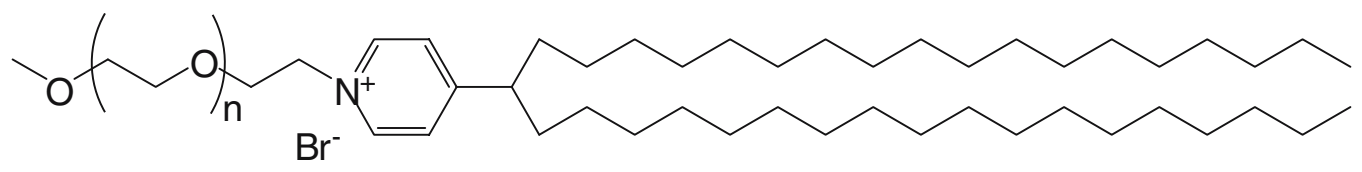

PEG-SAINT 18:0 $_{10}$

Fig. 4. Chemical structure of PEG-PE, PEG-Ceramides, PEG-diacylglycerols, PEG-dialkyloxypropylamines and PEG-SAINT.

PE conjugates were administered intravenously into mice. Plasma was collected after $16 \mathrm{~h}$. Subsequently the binding assay using SA-coated magnetic particles was performed. Extraction rates in vivo were comparable to the data obtained in vitro. The PEG-DSPE formulation did not show binding activity, indicating that the conjugate was not extracted from liposomes. The PEG-DMPE and a PEGDOPE formulation, on the other hand, showed $63 \%$ and $41 \%$ of the binding activity which was observed for nonPEGylated formulations after circulation in vivo. As the PEG-lipid conjugate transfer process occurs over a time scale of hours for PEG-DPPE or PEG-DOPE, a time scale allowing for significant liposome accumulation in tumors, the authors conclude that these systems can serve for actively targeted long-circulating liposomes exposing their targeting ligand in the tumor by shedding. To evaluate this system further, the potential of the different exchangeable PEGlipids to protect the model targeting ligand biotin from interaction with specific antibodies was investigated using PC/cholesterol liposomes with $0.1 \mathrm{~mol} \%$ of a biotin-conjugated lipid (63). In an in vitro antibody consumption assay, complete protection of the ligand with the usually applied $5 \mathrm{~mol} \%$ of PEG conjugate could only be obtained when using PEG-DSPE or PEG-DPPE, the conjugates with longer acyl chains. Mice with an existing immune response against biotin were challenged with these liposomes. It was observed that only for formulations that showed no antibody binding in vitro, effective protection against rapid 
elimination of the liposomes in vivo occurred. PEG-DMPE, the conjugate with the shortest acyl-chains, was not able to prolong liposome circulation times, likely as a result of its rapid extraction.

The influence of different PEG conjugates on the in vitro transfection efficiency of lipid-DNA particles (LDP) composed of plasmid DNA, n-octyl-D-glucopyranoside, DODAC, DOPE and exchangeable PEG-lipids was investigated (64). PEG-DSPE was used as a slow exchanging conjugate, and compared to PEG-DOPE and PEG-DMPE. All three formulations showed a significantly reduced transfection of B16/BL6 melanoma cells when compared to a nonPEGylated formulation. LPD with PEG-DMPE were the most transfection potent with still measurable gene expression at $10 \mathrm{~mol} \%$ coating density due to extraction from the bilayer. For PEG-DSPE LPD and PEG-DOPE LPD complete suppression of transfection was observed at $\geq 5 \mathrm{~mol} \%$ coating density and $\geq 2 \mathrm{~mol} \%$ coating density, respectively.

Mayer and colleagues studied the applicability of exchangeable PEG-PE conjugates on the surface of liposomes containing $10 \mathrm{~mol} \%$ phosphatidylserine (PS) (65). PS liposomes are able to induce coagulation by binding of clotting factors and, when delivered specifically to tumor sites, this coagulation can result in tumor regression. However, PS liposomes have to be shielded during circulation to avoid intravenous coagulation and rapid elimination. Liposomes with a PEG-conjugate grafting density of 10-15 mol\% were used. Forty percent of the PEG-DMPE conjugate was extracted out of the liposomes within 15 min after addition of acceptor PC/cholesterol liposomes. For the PEGDPPE conjugate the extraction rate was $45 \%$ in $24 \mathrm{~h}$. Transfer only occurred in the presence of acceptor liposomes. PEG-DSPE was not transferred to a significant extent within $24 \mathrm{~h}$. The clotting activity, resulting from exposure of the PS on the liposome surface after detachment of the PEGcoating, was assessed by measuring the partial thromboplastin time. While inhibition of clotting activity was constant over $24 \mathrm{~h}$ for the PEG-DSPE containing PS liposomes, for the PEG-DMPE PS liposomes the inhibition of clotting activity decreased to less than one third of its original value within $15 \mathrm{~min}$, likely caused by shedding of the liposome coating. For PEG-DPPE containing liposomes inhibition of clotting activity was reduced by half within $8 \mathrm{~h}$. Circulation time studies in mice showed that plasma levels of PEG-DSPE PS liposomes were clearly higher than those of the formulations containing PEG-DMPE and PEG-DSPE (more than $30 \%$ of the injected dose in the circulation at $4 \mathrm{~h}$ postinjection). For the latter formulations, less than $1 \%$ of the injected dose was still in the blood stream $4 \mathrm{~h}$ after administration. The authors conclude that the surface reactivity of PS-containing liposomes can be controlled by utilizing exchangeable PEG-lipids.

\section{PEG-Ceramide Conjugates}

PEG-ceramide conjugates (PEG-Cer, Fig. 4b) were proposed as alternatives for PEG-PE by the group of Madden (13). Cullis and coworkers compared PEG-Cer conjugates with various acyl chain lengths (66). Coating of liposomes with $5 \mathrm{~mol} \%$ of $\mathrm{PEG}-\mathrm{CerC}_{20}$ and $\mathrm{PEG}-\mathrm{CerC}_{24}$ conjugates resulted in prolonged circulation times in mice, comparable to liposomes prepared with PEG-DSPE. However, PEG coupled to shorter $\mathrm{C}_{8}$ and $\mathrm{C}_{14}$ ceramides did not alter i.v. pharmacokinetics as compared to non-coated liposomes, this likely as a result of rapid extraction of PEGceramides out of the liposomes after i.v. administration.

PEG-ceramides were also utilized to temporarily stabilize fusogenic, cationic liposomes for gene delivery purposes, with the aim to restore fusogenic activity by shedding of the coating after arrival at the target site (67). Fusogenic activity of liposomes was dependent on the acyl-chain length, as assessed by a lipid mixing assay. At $5 \mathrm{~mol} \%$ PEG-CerC $\mathrm{C}_{20}$ suppressed lipid mixing to a greater extent than PEG-CerC $\mathrm{C}_{14}$ (approximately $15 \%$ vs. $5 \%$ lipid mixing after $50 \mathrm{~min}$ of incubation). Circulation times in mice also were acyl-chain length- and therefore exchangeability-dependent, with formulations with longer chains being more potent stabilizers, resulting in more prolonged circulation times. For example, $30 \%$ of PEG-CerC 20 liposomes and only $7 \%$ of PEG-CerC liposomes were in the circulation $1 \mathrm{~h}$ after administration.

PEG-ceramides were also tested in SPLP formulations. SPLP composed of DOPE/DODAC, plasmid DNA and 10 mol\% PEG-Cer were produced by detergent dialysis (68). As expected, in vitro extraction was dependent on the acyl chain length. Conjugates with $\mathrm{C}_{8}$ and $\mathrm{C}_{14}$ chains were transferred in the time frame of minutes $(1.2 \mathrm{~min}$ and approx. $70 \mathrm{~min}$, respectively), $\mathrm{PEG}-\mathrm{CerC}_{20}$ stayed attached to the bilayer for up to 13 days $(68,69)$. The in vitro transfection efficiencies were also dependent on the length of the ceramide acyl chain. Inclusion of $10 \mathrm{~mol}_{\%} \mathrm{PEG}-\mathrm{CerC}_{14}$ resulted in approximately 10-fold higher gene expression in COS-7 cells as compared to the PEG-CerC ${ }_{20}$ containing formulation after 5 days of incubation (68). A 30-fold higher transfection level was achieved with SPLP containing PEG-CerC 8 as compared to those prepared with $\mathrm{PEG}-\mathrm{CerC}_{14}$ in $\mathrm{BHK}$ cells (70). Likely, there is a correlation between transfer rates and transfection efficiency; formulations with shorter acyl chains have a higher potential to associate with the cell membrane and fuse with the endosomal membrane after endocytosis. Pharmacokinetic studies in mice revealed that SPLP containing PEG-CerC $\mathrm{C}_{20}$ remained in the circulation for hours,

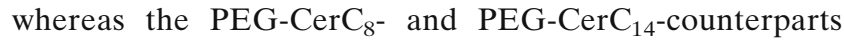
were cleared in 5 and $30 \mathrm{~min}$, respectively, which was likely a result of faster extraction and subsequent opsonization and uptake by macrophages $(69,71)$. The authors argue that conjugates with $\mathrm{C}_{16}$ or $\mathrm{C}_{18}$ alkyl chains might provide carriers with more optimal properties. However, this argument needs further experimental substantiation. SPLP with PEG-CerC $\mathrm{C}_{20}$ were shown to be able to also transfect tumor cells in vivo $(69,71,72)$. With this formulation, 43-fold more plasmid was delivered into the tumor site than with PEG-CerC ${ }_{14}$ SPLP. The role of shedding in successful in vivo transfection of PEG-CerC ${ }_{20}$ containing SPLP, however, remains unclear.

Programmable fusogenic liposomes (PFV, see $P E G$ Phosphatidylethanolamine Conjugates) prepared with PEGceramides were investigated by $\mathrm{Hu}$ and colleagues for the delivery of antisense ODN. PVF consisting of DOPE, DODAC, cholesterol and PEG-ceramides of different acylchain length were used (73). It appeared that PVF with PEG$\mathrm{CerC}_{14}$ yielded the best results regarding cytosolic delivery of ODN to HEK 293 cells when compared to $\mathrm{PEG}-\mathrm{CerC}_{8}$ and PEG-CerC ${ }_{20}$ PVF. ODN containing PVF with PEG-CerC $\mathrm{C}_{14}$ 
displayed lower and slower reduction of mRNA expression than non-coated control DOPE/DODAC/ODN liposomes, possibly related to the time needed for shedding and destabilization. Song et al. studied the effect of varying the acyl-chain length of PEG-Cer conjugates on the gene and antisense transfer into cells with cationic DOPE/DODAC liposomes (74). Anti-luciferase ODN-loaded liposomes with PEG-CerC $\mathrm{C}_{20}$ were not able to inhibit luciferase expression, the formulations with $\mathrm{C}_{14}$ and $\mathrm{C}_{8}$ ceramide anchors, however, showed significantly inhibited luciferase expression.

Shi et al. studied lipoplexes composed of DOPE, the cationic lipid $N$-methyl-4-(dioleyl)methylpyridinium chloride (SAINT-2) and PEG-CerC 8, PEG-CerC $_{14}$ or PEG-CerC 20 for the cellular delivery of ODN (75). Association with $\mathrm{CHO}$ cells and nuclear accumulation was dependent on ceramide chain length. After $2 \mathrm{~h}$ of incubation, nuclear accumulation of ODN was only seen for the formulation containing the PEG$\mathrm{CerC}_{8}$ conjugate. Overnight incubation of the cells with lipoplexes containing the $\mathrm{PEG}-\mathrm{CerC}_{8}$ and $\mathrm{PEG}-\mathrm{CerC}_{14}$ conjugates resulted in effective nuclear delivery and some delivery was seen for lipoplexes with PEG-CerC $\mathrm{C}_{20}$ lipoplexes. The antisense effect of lipoplexes in downregulation of CRF$\mathrm{R}$ expression in $\mathrm{CHO}$ cells was inversely correlated with the acyl chain length $\left(\mathrm{C}_{8}>\mathrm{C}_{14}>\mathrm{C}_{20}\right)$ which indicates that shedding of the PEG-coating is an essential requirement for the efficient delivery of ODN.

Stabilized antisense-lipid particles (SALP) composed of PC, cholesterol, DODAP, PEG-ceramide and antisense ODN were used to study the influence of the exchangeability of the PEG-coating on the immunogenicity of the carrier (22). Exchangeability was desired to abrogate the immunostimulatory effect of nucleic acids formulated in PEG-liposomes. When the slowly exchangeable PEG-CerC $\mathrm{C}_{20}$ was used as a stabilizing conjugate, particles were rapidly eliminated after a second injection. PEG-reactive IgM was detected in the blood of treated animals. Using PEG-CerC $\mathrm{C}_{14}$, where more than $50 \%$ of the conjugate was removed from the carrier within 3 min after administration, subsequent injections showed no differences in circulation kinetics, indicating a much weaker immune response than for the PEG-CerC ${ }_{20}$ containing formulation.

\section{PEG-Diacylglycerol Conjugates}

Ambegia et al. designed an SPLP formulation based DODAC and DOPE with a exchangeable coating using 10 mol\% PEG-succinoyl 1,2-diacylglycerol (PEG-S-DAG, Fig. 4c) (76). These conjugates were easier to synthesize and purify than PEG-ceramide conjugates. PEG-DMG $\left(\mathrm{C}_{14}\right)$, PEG-DPG $\left(\mathrm{C}_{16}\right)$, and PEG-DSG $\left(\mathrm{C}_{18}\right)$ were incorporated into SPLP and compared to PEG-ceramide containing SPLP regarding pharmacokinetics, biodistribution, and transfection properties. A lipid transfer assay based on FRET was used to analyze fusogenic properties of SPLP in vitro in the presence of 'sink' liposomes. SPLP prepared with PEG-DMG (with the shortest alkyl chain) were twice as fusogenic as compared to SPLP containing PEG-S-DAG with the longer alkyl chains. In line with these results, SPLP with the PEG-DMG yielded also the highest levels of gene expression in Neuro 2a cells. However, circulation time studies in mice showed that the SPLP formulation with the best in vitro performance
$\left(\mathrm{C}_{14}\right)$ was cleared very rapidly, likely due to a fast extraction of the PEG-coating. Both SPLP formulations with PEG coating anchored via the longer alkyl chains had comparable circulation times as compared to SPLP with PEG-CerC 20 . In mice bearing a s.c. Neuro-2a tumor, tumor accumulation (12\% injected dose/g tumor) and tumor gene expression was also highest for SPLP with PEG-DSG and PEG-DPG and comparable to SPLP with PEG-CerC 20 .

Judge et al. designed a carrier for the administration of nucleic acids (21). They observed that repeated administration of SPLP containing $10 \mathrm{~mol} \%$ PEG-S-DSG was associated with accelerated blood clearance and loss of gene expression and anti-PEG IgM and $\mathrm{IgG}$ were found. For SPLP containing PEG-S-DMG, the conjugate with shorter acyl chains and faster exchange rates, only low titers of IgM and no $\mathrm{IgG}$ were measured and no signs of toxicity were observed unlike with SPLP with the PEG-conjugate with a longer anchor. Tumor accumulation and gene expression of the SPLP with PEG-S-DMG were only twofold lower than with PEG-S-DSG. Expression after repeated administration of PEG-S-DMG SPLP was unaltered and blood clearance was only weakly affected.

\section{PEG-Dialkyloxypropylamine Conjugates}

Heyes et al. demonstrated that both PEG-S-DSG and PEG-CerC $\mathrm{C}_{20}$ were chemically unstable in lipoplex formulations due to the presence of carboxylic ester bonds in the succinate linker (77). Alternative linkers to couple PEG to 1,2-distearyloxypropyl-3-amine (DSA) and 1,2-dimyristyloxypropyl-3-amine (DMA), among which the carbamate linker (PEG-C-DSA, PEG-C-DMA, Fig. 4d), were synthesized. Circulation time studies in $\mathrm{A} / \mathrm{J}$ mice showed that SPLP containing PEG-C-DSA had a circulation half-life of $16 \mathrm{~h}$, whereas PEG-C-DMA containing SPLP were cleared much more rapidly with a half-life of $2 \mathrm{~h}$. The results regarding tumor gene delivery were comparable to those obtained with PEG-DAG with a lower gene expression for SPLP containing PEG-C-DMA than with SPLP containing PEG-C-DSA.

\section{PEG-SAINT Conjugates}

Reijman et al. synthesized exchangeable PEG conjugates employing the cationic lipid $N$-methyl-4-alkylpyridinium chloride (SAINT) as lipid anchor (Fig. 4e) (78). Lipoplexes of DOPE, a cationic lipid, a reporter plasmid with or without $5 \mathrm{~mol} \%$ of PEG-lipids, respectively, were prepared. The exchangeability of the PEG-SAINT conjugates was assessed in a DNA release assay in the presence of anionic vesicles to mimic endosomal escape and PC liposomes as acceptor membranes for the PEG conjugates. Exchange behavior was dependent on the alkyl-chain length. For the PEG-SAINT $12: 0$ and the PEG-SAINT $14: 0$ formulations (the subscript gives the number of carbon atoms per alkyl chain and the number of double bonds), DNA release was complete after $1-2 \mathrm{~h}$ and $8-10 \mathrm{~h}$, respectively, whereas the PEG-SAINT $18: 0$ formulation did not release DNA over a period of $18 \mathrm{~h}$. Transfection results showed the same acylchain length dependency. While lipoplexes prepared with the longest PEG-SAINT conjugate $\left(\mathrm{C}_{18}\right)$ and PEG-DSPE showed no transfection of B16 melanoma cells after 3 days, 
lipoplexes with the $\mathrm{C}_{12}$ and $\mathrm{C}_{16}$ anchors yielded about $60 \%$ transfected cells (comparable to the transfection activity of non-PEGylated formulations).

Table II summarizes approaches with shedding by spontaneous extraction out of the nanoparticle. For the conjugates with a PE anchor, acyl chain length dependent fusion could be demonstrated (13), however only PEG-DSPE showed long circulation times (61). Especially the PEGceramide conjugates were extensively studied. Particles with PEG-CerC $\mathrm{C}_{8}$ conjugate showed significant transfection in vitro but no prolonged circulation times and transfection in vivo (70). Particles with the $\mathrm{C}_{20}$ chain PEG-ceramide on the other hand that circulate sufficiently and transfect solid tumors in animals did not show high transfection levels in vitro (72). For exchangeable PEG-lipid conjugates in general, nanoparticle design is a compromise between prolongation of circulation times and protection of the carrier on the one hand, and a sufficient interaction of the carrier with the target and delivery on the other hand.

\section{Shedding by Degradation of the Coating Material Itself}

Besides coating conjugates with degradable linkers or exchangeable conjugates, shedding may also be pursued by the use of coating materials, which are fully biodegradable. Yet, these materials have to be able to act as 'stealth' coatings in the first place. In one approach, PEG has been chemically modified to introduce reduction-dependent degradation properties (79). The modified PEG polymer is sensitive to changes in redox-potential as a result of the introduction of disulfide bonds into the polymer backbone (poly(ethylene oxide sulfide), PEOS). The disulfide bonds were cleaved within two hours when exposed to reducing conditions resembling those encountered in the cytosol. Although circulation kinetics of nanoparticles coated with this material have not been studied yet, the potential of this material as a sheddable 'stealth' coating is obvious.

Recently, our research group reported on two poly (amino acid)-coatings based on (poly(hydroxyalkyl L-asparagine) (PHEA) and poly(hydroxyalkyl L-glutamine) (PHEG, Fig. 5) (8). Polypeptides of approximately 20 amino acids coupled to a lipid anchor were synthesized. The enzymatic degradability of the PHEG conjugate was demonstrated using the model proteases papain and pronase $\mathrm{E}$, and the lysosomal enzyme cathepsin $\mathrm{B}$, the latter being also present extracellularly in tumors and inflammatory tissue (80). All tested proteases were active towards the PHEG conjugate and degradation resulted in small peptide fragments. Liposomes coated with PHEA and PHEG showed almost similar circulation behavior in rats as compared to coating with PEG-DSPE (8).

There are only very few examples of fully degradable coatings for nanoparticles and only little is known about their degradation kinetics in vivo until now (see Table III for shedding approaches using degradable coating material). Nevertheless, these coatings represent an interesting alternative to linker-based shedding approaches.

\section{SUMMARY AND CONCLUSION}

Above, different shedding approaches have been highlighted. The choice of the most useful approach is dependent on factors like the presence of stimuli at the aimed shedding site (in the case of degradable linkers/coatings: low $\mathrm{pH}$, low redox potential, proteolytic enzymes). To avoid dependence on such stimuli, exchangeable coatings have been designed. However, in the latter case it is obvious that the rate of exchange should be tailored to the needs of the applications. In principle, the shedding approaches can also be categorized as follows (see also Fig. 1): Extracellular shedding in pathological or healthy tissue should lead to an enhanced drug release, with subsequent uptake of the free drug by the target cell $(29,34,61,66,80)$. Or exposure of a targeting ligand $(62,63)$, charge $(33,39,47,59,64)$, cell-penetrating peptide $(40,53)$ or fusogenic moiety $(67,73)$ 'buried' in the steric coating can be achieved by shedding, which would facilitate interaction of the particles with the cell membrane possibly followed by internalization. Intracellular shedding would lead to drug release within the endosome or interaction with the endosomal membrane for cytosolic release of the cargo $(30,32,35,36,41,42,44,46,50,51,54,74,78,80)$. Also, shedding of the coating within the cytosol from particles which have been translocated over the plasma membrane has been proposed as cytosolic delivery mechanism (53). In addition, sheddinginduced exposure of PS for tumor site specific coagulation (65) and shedding to reduce immunogenicity of nucleic acid containing PEG-coated carriers have been investigated $(21,22,77)$. As the shedding process in case of the carriers with exchangeable coatings are not dependent on the presence of a stimulus, the body location(s) where shedding occurs is governed by the kinetics of the exchange process and can be extra- or intracellular $(61,64,66,74)$. Among the degradable coatings, both degradable linkers and degradable coatings are applied. The advantage of a degradable linker

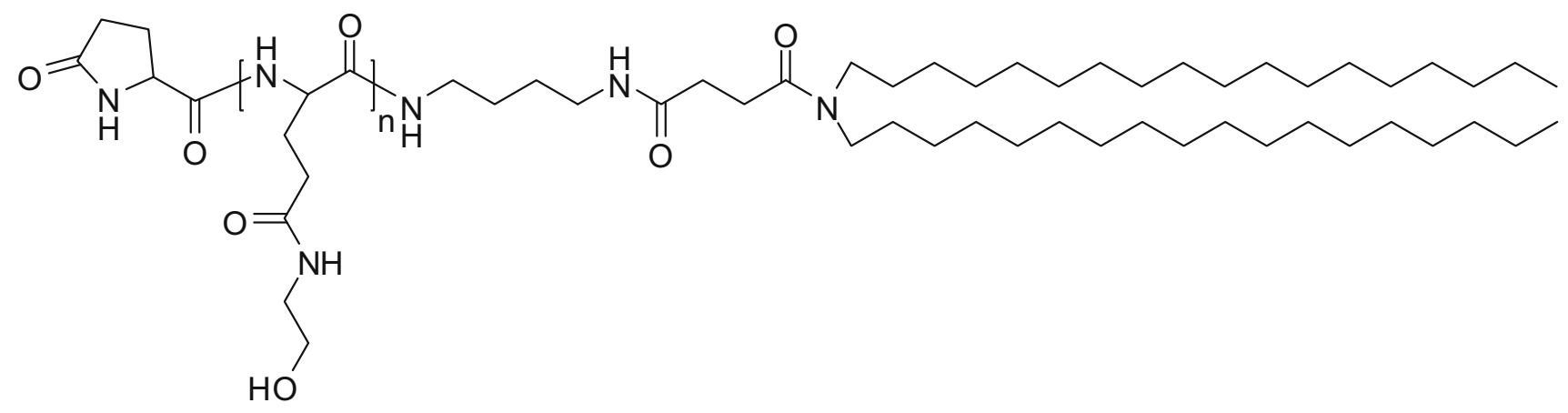

Fig. 5. Chemical structure of PHEG-lipid conjugate $(n \approx 20)$. 
may be that only one bond per polymer chain needs to be cleaved to detach a complete coating molecule from the carrier surface. This might imply a much faster and probably more complete shedding than when a fully degradable coating is applied, where more than one bond per coating molecule needs to be broken before the chains will be short enough to allow exposure of surface characteristics or destabilization. It should be realized, however, that a single linker bond, which is located deeply inside the shielding layer, might be quite inaccessible for the stimulus. For instance, a peptide linker might be difficult to reach for the proteolytic enzyme with obviously insufficient shedding as a result.

The shedding rate is a crucial parameter that has to be addressed when designing sheddable coatings. If premature shedding occurs, the unprotected carrier will likely be rapidly cleared from the circulation $(50,52,61,62,66,76)$. On the other hand, if shedding occurs at a too slow rate the therapeutic efficacy of the incorporated active agent may be too low $(35,36,49,51,62,64,68,74,78)$. Moreover, if shedding is incomplete, interaction of the carrier with its target or drug release might be poor.

Shedding of a stabilizing nanoparticle coating is an elegant tool to optimize the performance of particulate carriers in drug delivery. It would enable a controlled alteration of the properties of a particulate carrier on its way to the target, with the ultimate goal to improve the delivery of its cargo. In the past ten years investigations of several research groups generated promising results. 'Smart' chemistry allowed the design of functional conjugates, which for example respond to different stimuli present in the human body. However, it still remains a challenge to optimize the efficiency of these systems for successful in vivo application. Although several groups claim tailorable properties of their system, actual improvements in terms of drug delivery are only scarcely demonstrated. Most shedding studies so far were performed in vitro with a lack of demonstration of shedding under in vivo conditions. In this field, there is a lot of suggestion and only indirect evidence of shedding has been obtained in functional assays (e.g. transfection potency of a DNA loaded carrier). The design of studies on the shedding process itself and its kinetics in vivo is obviously difficult. Nevertheless, the current status reflects promising achievements on the road to the design of particulate nanomedicines with optimal therapeutic performance.

\section{REFERENCES}

1. V. P. Torchilin. Recent advances with liposomes as pharmaceutical carriers. Nat. Rev. Drug Discov. 4:145-160 (2005).

2. M. C. Woodle and D. D. Lasic. Sterically stabilized liposomes. Biochim. Biophys. Acta 1113:171-199 (1992).

3. M. C. Woodle, C. M. Engbers, and S. Zalipsky. New amphipatic polymer-lipid conjugates forming long-circulating reticuloendothelial system-evading liposomes. Bioconjug. Chem. 5:493-496 (1994).

4. H. Takeuchi, H. Kojima, H. Yamamoto, and Y. Kawashima. Evaluation of circulation profiles of liposomes coated with hydrophilic polymers having different molecular weights in rats. J. Control. Release 75:83-91 (2001).

5. K. Maruyama, S. Okuizumi, O. Ishida, H. Yamauchi, H. Kikuchi, and M. Iwatsuru. Phosphatidylpolyglycerols prolong liposome circulation in vivo. Int. J. Pharm. 111:103-107 (1994).
6. V. P. Torchilin, M. I. Shtilman, V. S. Trubetskoy, K. Whiteman and A. M. Milstein. Amphiphilic vinyl polymers effectively prolong liposome circulation time in vivo. Biochim. Biophys. Acta 1195:181-184 (1994).

7. K. Whiteman. Poly(HPMA)-coated liposomes demonstrate prolonged circulation in mice. Journal of Liposome Research 11:153-164 (2001).

8. J. M. Metselaar, P. Bruin, L. W. de Boer, T. de Vringer, C. Snel, C. Oussoren, M. H. Wauben, D. J. Crommelin, G. Storm, and W. E. Hennink. A novel family of L-amino acid-based biodegradable polymer-lipid conjugates for the development of longcirculating liposomes with effective drug-targeting capacity. Bioconjug. Chem. 14:1156-1164 (2003).

9. V. P. Torchilin and V. S. Trubetskoy. Which polymers can make nanoparticulate drug carriers long-circulating?. Adv. Drug Deliver. Rev. 16:141-155 (1995).

10. M. C. Woodle. Controlling liposome blood clearance by surfacegrafted polymers. Adv. Drug Deliv. Rev. 32:139-152 (1998).

11. H. Maeda, J. Wu, T. Sawa, Y. Matsumura, and K. Hori. Tumor vascular permeability and the EPR effect in macromolecular therapeutics: a review. J. Control. Release 65:271-284 (2000).

12. R. L. Hong, C. J. Huang, Y. L. Tseng, V. F. Pang, S. T. Chen, J. J. Liu, and F. H. Chang. Direct comparison of liposomal doxorubicin with or without polyethylene glycol coating in C26 tumor-bearing mice: is surface coating with polyethylene glycol beneficial?. Clin. Cancer Res. 5:3645-3652 (1999).

13. J. W. Holland, C. Hui, P. R. Cullis, and T. D. Madden. Poly (ethylene glycol)-lipid conjugates regulate the calcium-induced fusion of liposomes composed of phosphatidylethanolamine and phosphatidylserine. Biochemistry 35:2618-2624 (1996).

14. P. Erbacher, T. Bettinger, P. Belguise-Valladier, S. Zou, J. L. Coll, J. P. Behr, and J. S. Remy. Transfection and physical properties of various saccharide, poly(ethylene glycol), and antibody-derivatized polyethylenimines (PEI). J. Gene Med. 1:210-222 (1999).

15. C. R. Miller, B. Bondurant, S. D. McLean, K. A. McGovern, and D. F. O'Brien. Liposome-cell interactions in vitro: effect of liposome surface charge on the binding and endocytosis of conventional and sterically stabilized liposomes. Biochemistry 37:12875-12883 (1998).

16. T. M. Allen, E. Brandeis, C. B. Hansen, G. Y. Kao, and S. Zalipsky. A new strategy for attachment of antibodies to sterically stabilized liposomes resulting in efficient targeting to cancer cells. Biochim. Biophys. Acta 1237:99-108 (1995).

17. J. A. Harding, C. M. Engbers, M. S. Newman, N. I. Goldstein, and S. Zalipsky. Immunogenicity and pharmacokinetic attributes of poly(ethylene glycol)-grafted immunoliposomes. Biochim. Biophys. Acta 1327:181-192 (1997).

18. T. Kaasgaard, O. G. Mouritsen, and K. Jorgensen. Screening effect of PEG on avidin binding to liposome surface receptors. Int. J. Pharm. 214:63-65 (2001).

19. H. C. Loughrey, A. Ferraretto, A. M. Cannon, G. Acerbis, F. Sudati, G. Bottiroli, M. Masserini, and M. R. Soria. Characterisation of biotinylated liposomes for in vivo targeting applications. FEBS Lett. 332:183-188 (1993).

20. S. Simoes, J. N. Moreira, C. Fonseca, N. Duzgunes, and M. C. Pedroso De Lima. On the formulation of $\mathrm{pH}$-sensitive liposomes with long circulation times. Adv. Drug Deliv. Rev. 56:947-965 (2004).

21. A. Judge, K. McClintock, J. R. Phelps, and I. Maclachlan. Hypersensitivity and loss of disease site targeting caused by antibody responses to PEGylated liposomes. Molec. Ther. 13:328-337 (2006).

22. S. C. Semple, T. O. Harasym, K. A. Clow, S. M. Ansell, S. K Klimuk, and M. J. Hope. Immunogenicity and rapid blood clearance of liposomes containing polyethylene glycol-lipid conjugates and nucleic Acid. J. Pharmacol. Exp. Ther. 312:1020-1026 (2005).

23. F. M. Veronese and G. Pasut. PEGylation, successful approach to drug delivery. Drug Discov. Today 10:1451-1458 (2005).

24. A. Asokan and M. J. Cho. Exploitation of intracellular $\mathrm{pH}$ gradients in the cellular delivery of macromolecules. J. Pharm. Sci. 91:903-913 (2002).

25. I. F. Tannock and D. Rotin. Acid $\mathrm{pH}$ in tumors and its potential for therapeutic exploitation. Cancer Res. 49:4373-4384 (1989). 
26. K. H. Steen, A. E. Steen, and P. W. Reeh. A dominant role of acid $\mathrm{pH}$ in inflammatory excitation and sensitization of nociceptors in rat skin, in vitro. J. Neurosci. 15:3982-3989 (1995).

27. J. Levitsky, D. Gurell, and W. H. Frishman. Sodium ion/ hydrogen ion exchange inhibition: a new pharmacologic approach to myocardial ischemia and reperfusion injury. J. Clin. Pharmacol. 38:887-897 (1998).

28. M. Ahmad, R. G. Bergstrom, M. J. Cashen, Y. Chiang, A. J. Kresge, R. A. McClelland, and M. F. Powell. Ortho ester hydrolysis: direct evidence for a three-stage reaction mechanism. J. Am. Chem. Soc. 101:2669-2677 (1979).

29. X. Guo and F. C. Szoka Jr.. Steric stabilization of fusogenic liposomes by a low-pH sensitive PEG-diortho ester-lipid conjugate. Bioconjug. Chem. 12:291-300 (2001).

30. W. Li, Z. Huang, J. A. MacKay, S. Grube, and F. C. Szoka Jr. Low-pH-sensitive poly(ethylene glycol) (PEG)-stabilized plasmid nanolipoparticles: effects of PEG chain length, lipid composition and assembly conditions on gene delivery. J. Gene Med. 7:67-79 (2005).

31. X. Guo, J. A. MacKay, and F. C. Szoka Jr. Mechanism of pHtriggered collapse of phosphatidylethanolamine liposomes stabilized by an ortho ester polyethyleneglycol lipid. Biophys. J. 84:1784-1795 (2003).

32. J. S. Choi, J. A. MacKay, and F. C. Szoka Jr. Low-pH-sensitive PEG-stabilized plasmid-lipid nanoparticles: preparation and characterization. Bioconjug. Chem. 14:420-429 (2003).

33. C. Masson, M. Garinot, N. Mignet, B. Wetzer, P. Mailhe, D. Scherman, and M. Bessodes. pH-sensitive PEG lipids containing orthoester linkers: new potential tools for nonviral gene delivery. J. Control. Release 99:423-434 (2004).

34. J. Shin, P. Shum, and D. H. Thompson. Acid-triggered release via dePEGylation of DOPE liposomes containing acidlabile vinyl ether PEG-lipids. J. Control. Release 91:187-200 (2003).

35. N. Bergstrand, M. C. Arfvidsson, J. M. Kim, D. H. Thompson, and K. Edwards. Interactions between $\mathrm{pH}$-sensitive liposomes and model membranes. Biophys. Chem. 104:361-379 (2003).

36. J. A. Boomer, H. D. Inerowicz, Z. Zhang, N. Bergstrand, K. Edwards, J. M. Kim, and D. H. Thompson. Acid-triggered release from sterically stabilized fusogenic liposomes via a hydrolytic dePEGylation strategy. Langmuir 19:6408-6415 (2003).

37. J. A. Boomer and D. H. Thompson. Synthesis of acid-labile diplasmenyl lipids for drug and gene delivery applications. Chem. Phys. Lipids 99:145-153 (1999).

38. O. V. Gerasimov, J. A. Boomer, M. M. Qualls, and D. H. Thompson. Cytosolic drug delivery using $\mathrm{pH}$ - and light-sensitive liposomes. Adv. Drug Deliv. Rev. 38:317-338 (1999).

39. J. H. Jeong, S. W. Kim, and T. G. Park. Novel intracellular delivery system of antisense oligonucleotide by self-assembled hybrid micelles composed of DNA/PEG conjugate and cationic fusogenic peptide. Bioconjug. Chem. 14:473-479 (2003).

40. R. M. Sawant, J. P. Hurley, S. Salmaso, A. Kale, E. Tolcheva, T. S. Levchenko, and V. P. Torchilin. "SMART" drug delivery systems: double-targeted $\mathrm{pH}$-responsive pharmaceutical nanocarriers. Bioconjug. Chem. 17:943-949 (2006).

41. G. F. Walker, C. Fella, J. Pelisek, J. Fahrmeir, S. Boeckle, M. Ogris, and E. Wagner. Toward synthetic viruses: endosomal $\mathrm{pH}$-triggered deshielding of targeted polyplexes greatly enhances gene transfer in vitro and in vivo. Molec. Ther. 11:418-425 (2005).

42. M. Oishi, S. Sasaki, Y. Nagasaki, and K. Kataoka. pH-responsive oligodeoxynucleotide (ODN)-poly(ethylene glycol) conjugate through acid-labile beta-thiopropionate linkage: preparation and polyion complex micelle formation. Biomacromolecules 4:1426-1432 (2003).

43. M. Oishi, F. Nagatsugi, S. Sasaki, Y. Nagasaki, and K. Kataoka. Smart polyion complex micelles for targeted intracellular delivery of PEGylated antisense oligonucleotides containing acid-labile linkages. ChemBioChem 6:718-725 (2005).

44. M. Oishi, Y. Nagasaki, K. Itaka, N. Nishiyama, and K. Kataoka. Lactosylated poly(ethylene glycol)-siRNA conjugate through acid-labile beta-thiopropionate linkage to construct $\mathrm{pH}$-sensitive polyion complex micelles achieving enhanced gene silencing in hepatoma cells. J. Am. Chem. Soc. 127:1624-1625 (2005).
45. D. Finsinger, J. S. Remy, P. Erbacher, C. Koch, and C. Plank. Protective copolymers for nonviral gene vectors: synthesis, vector characterization and application in gene delivery. Gene Ther. 7:1183-1192 (2000).

46. D. T. Auguste, S. P. Armes, K. R. Brzezinska, T. J. Deming, J. Kohn, and R. K. Prud'homme. pH triggered release of protective poly(ethylene glycol)-b-polycation copolymers from liposomes. Biomaterials 27:2599-2608 (2006).

47. V. A. Sethuraman, K. Na, and Y. H. Bae. pH-responsive sulfonamide/PEI system for tumor specific gene delivery: an in vitro study. Biomacromolecules 7:64-70 (2006).

48. G. Saito, J. A. Swanson, and K. D. Lee. Drug delivery strategy utilizing conjugation via reversible disulfide linkages: role and site of cellular reducing activities. Adv. Drug Deliv. Rev. 55:199215 (2003).

49. D. Kirpotin, K. Hong, N. Mullah, D. Papahadjopoulos, and S. Zalipsky. Liposomes with detachable polymer coating: destabilization and fusion of dioleoylphosphatidylethanolamine vesicles triggered by cleavage of surface-grafted poly(ethylene glycol). FEBS Lett. 388:115-118 (1996).

50. T. Ishida, M. J. Kirchmeier, E. H. Moase, S. Zalipsky, and T. M. Allen. Targeted delivery and triggered release of liposomal doxorubicin enhances cytotoxicity against human B lymphoma cells. Biochim. Biophys. Acta 1515:144-158 (2001).

51. J. X. Zhang, S. Zalipsky, N. Mullah, M. Pechar, and T. M. Allen. Pharmaco attributes of dioleoylphosphatidylethanolamine/cholesterylhemisuccinate liposomes containing different types of cleavable lipopolymers. Pharmacol. Res. 49:185-198 (2004).

52. S. Zalipsky, M. Qazen, J. A. Walker, 2nd, N. Mullah, Y. P. Quinn, and S. K. Huang. New detachable poly(ethylene glycol) conjugates: cysteine-cleavable lipopolymers regenerating natural phospholipid, diacyl phosphatidylethanolamine. Bioconjug. Chem. 10:703-707 (1999).

53. T. Maeda and K. Fujimoto. A reduction-triggered delivery by a liposomal carrier possessing membrane-permeable ligands and a detachable coating. Colloids Surf. B Biointerfaces 49:15-21 (2006).

54. R. C. Carlisle, T. Etrych, S. S. Briggs, J. A. Preece, K. Ulbrich, and L. W. Seymour. Polymer-coated polyethylenimine/DNA complexes designed for triggered activation by intracellular reduction. J. Gene Med. 6:337-344 (2004).

55. X. Guo and F. C. Szoka Jr. Chemical approaches to triggereable lipid vesicles for drug and gene delivery. Acc. Chem. Res. 36:335-341 (2003).

56. A. Trabandt, R. E. Gay, H. G. Fassbender, and S. Gay. Cathepsin B in synovial cells at the site of joint destruction in rheumatoid arthritis. Arthritis Rheum. 34:1444-1451 (1991).

57. J. E. Koblinski, M. Ahram, and B. F. Sloane. Unraveling the role of proteases in cancer. Clin. Chim. Acta 291:113-135 (2000).

58. P. Meers. Enzyme-activated targeting of liposomes. Adv. Drug Deliv. Rev. 53:265-272 (2001).

59. H. Hatakeyama, H. Akita, K. Kogure, M. Oishi, Y. Nagasaki, Y. Kihira, M. Ueno, H. Kobayashi, H. Kikuchi, and H. Harashima. Development of a novel systemic gene delivery system for cancer therapy with a tumor-specific cleavable PEG-lipid. Gene Ther. 14:68-77 (2007).

60. J. R. Silvius and M. J. Zuckermann. Interbilayer transfer of phospholipid-anchored macromolecules via monomer diffusion. Biochemistry 32:3153-3161 (1993).

61. G. Adlakha-Hutcheon, M. B. Bally, C. R. Shew, and T. D. Madden. Controlled destabilization of a liposomal drug delivery system enhances mitoxantrone antitumor activity. Nat. Biotechnol. 17:775-779 (1999).

62. W. M. Li, L. Xue, L. D. Mayer, and M. B. Bally. Intermembrane transfer of polyethylene glycol-modified phosphatidylethanolamine as a means to reveal surface associated binding ligands on liposomes. Biochim. Biophys. Acta 1513:193-206 (2001).

63. W. M. Li, L. D. Mayer, and M. B. Bally. Prevention of antibodymediated elimination of ligand-targeted liposomes by using poly(ethylene glycol)-modified lipids. J. Pharm. Exp. Ther. 300:976-983 (2001).

64. P. Harvie, F. M. Wong, and M. B. Bally. Use of poly(ethylene glycol)-lipid conjugates to regulate the surface attributes and transfection activity of lipid-DNA particles. J. Pharm. Sci. 89:652-663 (2000). 
65. G. N. Chiu, M. B. Bally, and L. D. Mayer. Effects of phosphatidylserine on membrane incorporation and surface protection properties of exchangeable poly(ethylene glycol)conjugated lipids. Biochim. Biophys. Acta 1560:37-50 (2002)

66. M. S. Webb, D. Saxon, F. M. Wong, H. J. Lim, Z. Wang, M. B. Bally, L. S. Choi, P. R. Cullis, and L. D. Mayer. Comparison of different hydrophobic anchors conjugated to poly(ethylene glycol): effects on the pharmacokinetics of liposomal vincristine. Biochim. Biophys. Acta 1372:272-282 (1998).

67. A. Mori, A. Chonn, L. S. Choi, A. Israels, M. A. Monck, and P. R. Cullis. Stabilization and regulated fusion of liposomes containing a cationic lipid using amphipathic polyethyleneglycol derivatives. J. Liposome Res. 8:195-211 (1998).

68. J. J. Wheeler, L. Palmer, M. Ossanlou, I. MacLachlan, R. W. Graham, Y. P. Zhang, M. J. Hope, P. Scherrer, and P. R. Cullis. Stabilized plasmid-lipid particles: construction and characterization. Gene Ther. 6:271-281 (1999).

69. D. B. Fenske, I. MacLachlan, and P. R. Cullis. Stabilized plasmid-lipid particles: a systemic gene therapy vector. Methods Enzymol. 346:36-71 (2002).

70. K. W. Mok, A. M. Lam, and P. R. Cullis. Stabilized plasmid-lipid particles: factors influencing plasmid entrapment and transfection properties. Biochim. Biophys. Acta 1419:137-150 (1999).

71. M. A. Monck, A. Mori, D. Lee, P. Tam, J. J. Wheeler, P. R. Cullis, and P. Scherrer. Stabilized plasmid-lipid particles: pharmacokinetics and plasmid delivery to distal tumors following intravenous injection. J. Drug Target 7:439-452 (2000).

72. P. Tam, M. Monck, D. Lee, O. Ludkovski, E. C. Leng, K. Clow, H. Stark, P. Scherrer, R. W. Graham, and P. R. Cullis. Stabilized plasmid-lipid particles for systemic gene therapy. Gene Ther. 7:1867-1874 (2000).

73. Q. Hu, C. R. Shew, M. B. Bally, and T. D. Madden. Programmable fusogenic vesicles for intracellular delivery of antisense oligodeoxynucleotides: enhanced cellular uptake and biological effects. Biochim. Biophys. Acta 1514:1-13 (2001).

74. L. Y. Song, Q. F. Ahkong, Q. Rong, Z. Wang, S. Ansell, M. J. Hope, and B. Mui. Characterization of the inhibitory effect of PEG-lipid conjugates on the intracellular delivery of plasmid and antisense DNA mediated by cationic lipid liposomes. Biochim. Biophys. Acta 1558:1-13 (2002).

75. F. Shi, L. Wasungu, A. Nomden, M. C. Stuart, E. Polushkin, J. B. Engberts, and D. Hoekstra. Interference of poly(ethylene glycol)-lipid analogues with cationic-lipid-mediated delivery of oligonucleotides; role of lipid exchangeability and non-lamellar transitions. Biochem. J. 366:333-341 (2002).

76. E. Ambegia, S. Ansell, P. Cullis, J. Heyes, L. Palmer, and I. MacLachlan. Stabilized plasmid-lipid particles containing PEGdiacylglycerols exhibit extended circulation lifetimes and tumor selective gene expression. Biochim. Biophys. Acta 1669:155-163 (2005).

77. J. Heyes, K. Hall, V. Tailor, R. Lenz, and I. MacLachlan. Synthesis and characterization of novel poly(ethylene glycol)lipid conjugates suitable for use in drug delivery. J. Control. Release 112:280-290 (2006).

78. J. Rejman, A. Wagenaar, J. B. Engberts, and D. Hoekstra. Characterization and transfection properties of lipoplexes stabilized with novel exchangeable polyethylene glycol-lipid conjugates. Biochim. Biophys. Acta 1660:41-52 (2004).

79. Y. Lee, H. Koo, G. Jin, H. Mo, M. J. Cho, J. Park, J. S. Choi, and J. S. Park. Poly(ethylene oxide sulfide): new poly(ethylene glycol) derivatives degradable in reductive conditions. Biomacromolecules 6:24-26 (2005).

80. B. Romberg, J. M. Metselaar, T. de Vringer, K. Motonaga, J. J. Kettenes-van den Bosch, C. Oussoren, G. Storm, and W. E. Hennink. Enzymatic degradation of liposome-grafted poly(hydroxyethyl l-glutamine). Bioconjug. Chem. 16:767-774 (2005). 